\title{
The nucleus reuniens of the thalamus sits at the nexus of a hippocampus and medial prefrontal cortex circuit enabling memory and behavior
}

\author{
Margriet J. Dolleman-van der Weel, ${ }^{1,2}$ Amy L. Griffin, ${ }^{3}$ Hiroshi T. Ito, ${ }^{4}$ \\ Matthew L. Shapiro, ${ }^{5}$ Menno P. Witter, ${ }^{6}$ Robert P. Vertes, ${ }^{7}$ and Timothy A. Allen ${ }^{8,9}$ \\ ${ }^{1}$ Department of Anatomy and Neurosciences, VU University Medical Center, Amsterdam NL-1007MB, The Netherlands; ${ }^{2}$ Center for \\ Neuroscience, Swammerdam Institute for Life Sciences, University of Amsterdam, Amsterdam NL-1098XH, The Netherlands; \\ ${ }^{3}$ Department of Psychological and Brain Sciences, University of Delaware, Newark, Delaware 19716, USA; ${ }^{4}$ Max Planck Institute for \\ Brain Research, 60438, Frankfurt am Main, Germany; ${ }^{5}$ Department of Neuroscience and Experimental Therapeutics, Albany Medical \\ College, Albany, New York 12208, USA; ${ }^{6}$ Kavli Institute for Systems Neuroscience and Centre for Neural Computation, NTNU \\ Norwegian University of Science and Technology, Trondheim NO-7491, Norway; ${ }^{7}$ Center for Complex Systems and Brain Sciences, \\ Florida Atlantic University, Boca Raton, Florida 33431, USA; ${ }^{8}$ Cognitive Neuroscience Program, Department of Psychology, Florida \\ International University, Miami, Florida 33199, USA; ${ }^{9}$ Department of Environmental Health Sciences, Florida International University, \\ Miami, Florida 33199, USA
}

\begin{abstract}
The nucleus reuniens of the thalamus (RE) is a key component of an extensive network of hippocampal and cortical structures and is a fundamental substrate for cognition. A common misconception is that RE is a simple relay structure. Instead, a better conceptualization is that RE is a critical component of a canonical higher-order cortico-thalamo-cortical circuit that supports communication between the medial prefrontal cortex (mPFC) and the hippocampus (HC). RE dysfunction is implicated in several clinical disorders including, but not limited to Alzheimer's disease, schizophrenia, and epilepsy. Here, we review key anatomical and physiological features of the RE based primarily on studies in rodents. We present a conceptual model of RE circuitry within the mPFC-RE-HC system and speculate on the computations RE enables. We review the rapidly growing literature demonstrating that $\mathrm{RE}$ is critical to, and its neurons represent, aspects of behavioral tasks that place demands on memory focusing on its role in navigation, spatial working memory, the temporal organization of memory, and executive functions.
\end{abstract}

\section{The importance of mPFC-HC interactions}

Adaptive behavior and mental health require the integration of motivation, attention, memory, and the outcome of past actions as relevant circumstances change. Particularly in similar situations, goals are best achieved by adjusting actions according to expected outcomes that change with the current time and one's location (e.g., wanting coffee and remembering which shop is open and nearby). This cognitive flexibility necessitates incorporating the outcomes of many episodes, and requires interactions between the medial prefrontal cortex (mPFC) and hippocampus (HC). Bidirectional interactions between the two structures result in an intentionrecollection cycle (Fuster 1995) that may reasonably describe how their complementary and distinct functions contribute to adaptive behavior. Beyond "what, where, and when," the external facts that define episodes (Morris 2001), hippocampal representations include "why and how." These internal features include outcome expectancies and abstract rules computed by the mPFC. Thus, mPFC signals relayed to $\mathrm{HC}$ can help guide both memory acquisition and retrieval. The HC signals relayed to $\mathrm{MPFC}$ allow remembered events to select associated goals, rules, and procedural representations. Importantly, mPFC-HC interactions depend heavily on the nucleus reuniens (RE), a thalamic region positioned at the center of a higher-order cortico-thalamo-cortical circuit bridging memory

\section{Corresponding author: tallen@fiu.edu}

Article is online at http://www.learnmem.org/cgi/doi/10.1101/lm.048389.118. Freely available online through the Learning \& Memory Open Access option. and executive function. Not surprisingly, RE is emerging as a focus for research on the neurobiological substrates of learning and memory.

\section{Anatomy and physiology of RE}

The anatomy and physiology of RE is essential for understanding its mechanistic contributions to the mPFC-HC system, and helps describe how RE is central to a wide array of cognitive and behavioral functions. RE has been the focus of anatomical and physiological studies in rodents for many years, and a homologous structure in humans has been described and associated with the interthalamic adhesion (e.g., Baydin et al. 2016) although it has received less attention, especially in functional studies (but see Reagh et al. 2017).

\section{Connections of RE with the limbic forebrain}

RE lies ventrally on the midline, directly above the third ventricle, and extends longitudinally virtually throughout the thalamus. The largest of the midline thalamic nuclei, RE is notable for linking limbic subcortical to cortical structures (for review, see Vertes et al.

(C) 2019 Dolleman-van der Weel et al. This article, published in Learning \& Memory, is available under a Creative Commons License (AttributionNonCommercial 4.0 International), as described at http://creativecommons. org/licenses/by-nc/4.0/. 
2015). RE is generally subdivided into a central (or medial) portion and lateral segments that have been designated the lateral wings of $\mathrm{RE}$, or the peri-reuniens nucleus (periRE). RE receives a diverse and widely distributed set of projections from limbic-related sites of the brainstem, hypothalamus, amygdala, basal forebrain, and limbic cortex (Vertes 2002, 2004; McKenna and Vertes 2004). However, unlike the widespread inputs to RE, the projections from RE are virtually restricted to "limbic" cortical sites; that is, to the orbital and medial PFC, the retrosplenial cortex, the parahippocampal region (perirhinal and entorhinal cortices) and the HC-including all parts of subicular cortices (Vertes 2006; Vertes et al. 2006).

RE projects substantially to the infralimbic (IL), prelimbic (PL), and anterior cingulate (AC) cortices of the $\mathrm{mPFC}$ with fibers terminating densely in layer 1 and layers $5 / 6$ of these regions. RE projections to the mPFC predominantly (but not exclusively) originate from the periRE nucleus (Hoover and Vertes 2012; Varela et al. 2014). The mPFC is a pronounced source of return projections to $\mathrm{RE}$, distributing throughout $\mathrm{RE}$, indicating strong reciprocal connections between RE/periRE and the mPFC. The mPFC also innervates the thalamic reticular nucleus (TRN) which, in turn, exerts feedforward inhibitory actions on RE (Fig. 1; McKenna and Vertes 2004)

Within the HC, RE innervates selectively CA1 and the subiculum of the dorsal, intermediate and ventral HC. No RE axons project to the dentate gyrus or to CA2/CA3. RE fibers terminate in the stratum lacunosum-moleculare (slm) of CA1 and in the outer molecular layer of the subiculum (Wouterlood et al. 1990; Vertes et al. 2006). Although RE distributes to the dorsal HC (CA1), RE projections are approximately 10 -fold stronger to ventral than to dorsal CA1 (Hoover and Vertes 2012; Varela et al. 2014). Recent examinations of the output of RE to its two main cortical targets, the mPFC and $\mathrm{HC}$ has shown that $\sim 5 \%-10 \%$ of RE neurons distribute, via axon collaterals, to both structures (Hoover and Vertes 2012; Varela et al. 2014). The RE cells projecting to the HC or mPFC are somewhat segregated; that is, those distributing to $\mathrm{HC}$ tended to cluster at the rostral pole of RE, whereas those projecting to $\mathrm{MPFC}$ are predominantly located in periRE and in caudal RE (Hoover and Vertes 2012; Varela et al. 2014). This segregation suggests an anatomical, and perhaps functional, differentiation within RE wherein separate subpopulations of RE neurons may exert their primary

\section{The mPFC-RE-HC System}

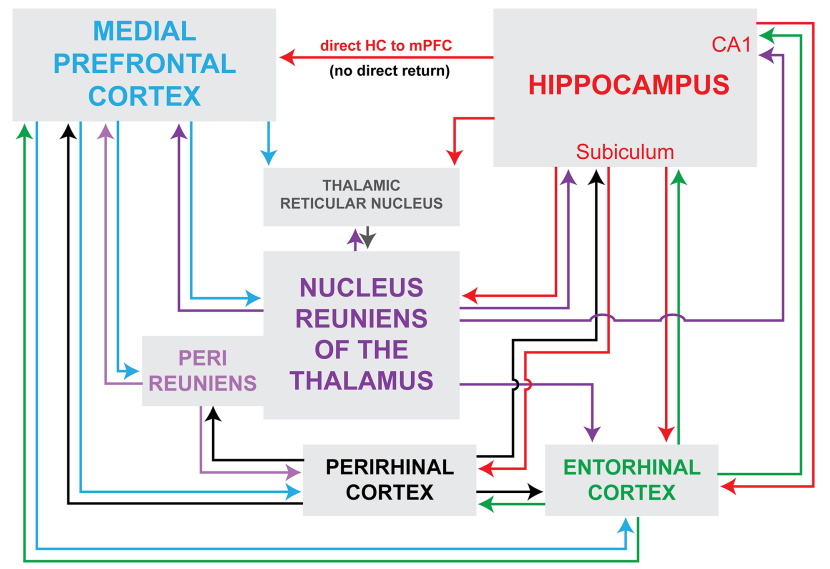

Figure 1. Schematic representation of the connectivity in the MPFC-RE$\mathrm{HC}$ system. The $\mathrm{HC}$ projects directly to the $\mathrm{MPFC}$, but there are no direct return projections. RE (including periRE) thus serves as the main link completing an HC-mPFC loop as follows: $\mathrm{HC} \rightarrow \mathrm{mPFC} \rightarrow \mathrm{RE} \rightarrow \mathrm{HC}$. Abbreviations: (HC) hippocampus, (mPFC) medial prefrontal cortex, (periRE) peri-reuniens nucleus, (RE) the nucleus reuniens of the thalamus. influence commonly on the HC (i.e., CA1 and subiculum) and mPFC, or perhaps selectively on either the HC (Dolleman-van der Weel and Witter 1996) or mPFC. As the mPFC strongly targets RE (Vertes 2002, 2004), there are equally dense projections from HC, or ventral subiculum, to RE (McKenna and Vertes 2004). In effect, $\mathrm{RE}$ is strongly reciprocally linked to $\mathrm{HC}$ and to $\mathrm{mPFC}$.

Although the (intermediate/ventral) HC projects directly to mPFC (Jay and Witter 1991; Hoover and Vertes 2007), interestingly, there are no (direct) return projections from mPFC to $\mathrm{HC}$ (Laroche et al. 2000). Rather, RE appears to be the main link returning projections from the $\mathrm{mPFC}$ to the $\mathrm{HC}$, thus completing a loop between these structures: $\mathrm{HC} \rightarrow \mathrm{mPFC} \rightarrow \mathrm{RE} \rightarrow \mathrm{HC}$. Although the perirhinal (PRC) and entorhinal cortices (EC) comprise additional relays from the $\mathrm{mPFC}$ to the $\mathrm{HC}$, it should be noted that RE also projects to both the PRC (via periRE) and EC, and therefore may also modulate information transferred from the mPFC to the HC, via PRC, and EC. Finally, although recent behavioral studies have focused on RE as a link between the mPFC and the HC, it is also the case (but often overlooked) that RE is an important (indirect) route from the $\mathrm{HC}$ to the $\mathrm{mPFC}$ - thus connecting these structures in the opposite direction: $\mathrm{HC} \rightarrow \mathrm{RE} \rightarrow \mathrm{mPFC}$. This pathway may exert return hippocampal modulatory effects on the mPFC and/or may serve as a critical route for the actions of the dorsal HC (dorsal subiculum) on the mPFC, especially in light of very minor direct projections from the dorsal HC to the mPFC (Hoover and Vertes 2007; DeNardo et al. 2015; Ye et al. 2017).

\section{Neurochemistry and physiology of RE}

$\mathrm{RE}$ is thought to play a key role in cognitive and executive processes, likely by orchestrating the communication between $\mathrm{mPFC}$ and HC. Insight in the underlying mechanisms requires a detailed anatomical and electrophysiological knowledge of their interconnectivity. Data on the synaptic organization and physiology of RE remain sparse. For instance, RE target cells have been studied anatomically and/or electrophysiologically in HC and EC (Wouterlood et al. 1990; Wouterlood 1991; Dolleman-van der Weel et al. 1997, 2017; Dolleman-van der Weel and Witter 2000), but similar investigations are lacking for the RE $\rightarrow$ mPFC pathway (e.g., Cruikshank et al. 2012). To advance insight in the functioning of RE, we summarize the neurochemistry of RE neurons, review electrophysiological data regarding the projections between RE, CA1, EC, and $\mathrm{mPFC}$, and finally discuss data on coupling of (rhythmic) neuronal activities in HC and mPFC through RE-mediated synchronization.

\section{Neurochemical characteristics of RE}

The primary neurotransmitter for RE is an excitatory amino acid, presumably aspartate and/or glutamate (e.g., Herkenham 1978; Bokor et al. 2002; Cruikshank et al. 2012). Accordingly, RE neurons form asymmetrical (i.e., excitatory) synapses on both pyramidal cells and interneurons in CA1, subiculum, and EC (Wouterlood et al. 1990; Wouterlood 1991; Dolleman-van der Weel and Witter 2000). Recently, dopamine-positive neurons were found in RE (Ogundele et al. 2017), which are suggested to be part of a hypothalamic neuroendocrine system. RE neurons are devoid of the inhibitory neurotransmitter $\gamma$-aminobutyric acid (GABA), indicating the absence of inhibitory interneurons in RE (Ottersen and Storm-Mathisen 1984).

In addition, RE is devoid of the calcium-binding protein parvalbumin (PV) which is expressed in (subclasses of) GABAergic interneurons as well as in thalamic relay cells. Instead RE neurons contain the calcium-binding proteins calretinin (CR), calbindin (CB), and coexpress CR/CB (Frassoni et al. 1991; Arai et al. 1994; Montpied et al. 1995; Bokor et al. 2002; Drexel et al. 2011). The 
absence of PV cells is important because CB- and PV-positivity $\left(^{+}\right.$) in thalamic neurons distinguish two classes of relay cells, namely $\mathrm{CB}^{+}$"matrix" cells with dense terminations in cortical layer 1 , and $\mathrm{PV}^{+}$"core" cells projecting to the middle cortical layers $3 / 4$ (Jones 1998). RE neurons are thus considered to be matrix cells, projecting predominantly to cortical layer 1 , but also innervating layers 5/6 (Vertes et al. 2006), overlapping with hippocampal axons in mPFC (Jay and Witter 1991; Gabbott et al. 2002).

\section{Physiology of RE connections}

The neurochemical diversity of RE neurons is likely associated with their function (Walsh et al. 2017). For example, thalamic midline CR-negative $\left(\mathrm{CR}^{-}\right)$and $\mathrm{CR}$-positive (i.e., $\mathrm{CR}^{+}$and $\mathrm{CR}^{+} / \mathrm{CB}^{+}$) neurons are differentially active during characteristic memory-related hippocampal network dynamics (Lara-Vásquez et al. 2016). These investigators showed that at theta frequencies $(4-10 \mathrm{~Hz})$ that are prominent during exploration and rapid eye movement (REM) sleep, $\mathrm{CR}^{-}$neurons display firing increases, whereas $\mathrm{CR}^{+}$neurons do not. In contrast, during sharp wave-ripples (SWR) that are prominent during quiet state $\leq 1 \mathrm{~Hz}$ slow oscillations and slow-wave sleep, the firing rate of the $\mathrm{CR}^{-}$neurons remains unaffected. However, $\mathrm{CR}^{+}$neurons are inhibited during a SWR event, but increase their firing just before and after (Lara-Vásquez et al. 2016). Thus $\mathrm{CR}^{+}$(including $\mathrm{CR}^{+} / \mathrm{CB}^{+}$) and single $\mathrm{CB}^{+} \mathrm{RE}$ projections to CA1, subiculum, and EC, may play different roles in, for instance, working memory (theta frequency-dependent) and memory consolidation (slow $\leq 1 \mathrm{~Hz}$ oscillations-dependent).

Surprisingly few electrophysiological studies have examined RE-elicited responses in HC and mPFC (Dollemanvan der Weel et al. 1997, 2017; Bertram and Zhang 1999; Zhang and Bertram 2002; Viana Di Prisco and Vertes 2006; Morales et al. 2007; Eleore et al. 2011; Cruikshank et al. 2012). In HC, Dolleman-van der Weel et al. (1997) used anesthetized rats to demonstrate that $\mathrm{RE}$ modulates the excitability of CA1 neurons through direct excitatory and indirect inhibitory mechanisms. RE axons in slm form asymmetrical (i.e., excitatory) synaptic contacts on the dendrites and spines of CA1 pyramidal cells (Wouterlood et al. 1990) and on GABA-positive interneurons (Dolleman-van der Weel and Witter 2000). Dolleman-van der Weel et al. (1997) showed that electrical stimulation of the RE resulted in a local field potential (LFP) response indicative of an excitatory synaptic effect in slm. Paired pulse $(0.1-10 \mathrm{~Hz})$ stimulation elicited larger amplitude field excitatory postsynaptic potentials (fEPSPs) at $0.1-2 \mathrm{~Hz}$ stimulation than at theta frequencies $(4-10 \mathrm{~Hz})$. However, despite the strong RE-induced paired pulse facilitation (PPF), firing in principal cells was not observed. In contrast, low frequency $(0.1-2$ $\mathrm{Hz}$ ) stimulation of RE resulted in driving radiatum interneurons, presumably Schaffer collateral-associated cells, and vertical oriens/alveus interneurons, both mediating feedforward inhibition of pyramidal cells. The inability of RE to generate reticular nucleus. spiking in CA1 pyramidal cells in anesthetized rats was confirmed in later studies (Morales et al. 2007; Eleore et al. 2011; Dollemanvan der Weel et al. 2017). However, one study has reported that electrical stimulation of the thalamic midline region, including $\mathrm{RE}$, evoked CA1 population spikes, similar to those evoked by contralateral CA3 stimulation (Bertram and Zhang 1999). This discrepancy with other reports may be due to the much larger thalamic region that was stimulated by the latter investigators. In addition to a clear monosynaptic RE input to CA1, there are indications for complex and presumably polysynaptic elicited field potentials in CA1 through a projection from caudal RE to rostral RE (Dolleman-van der Weel et al. 1997). This suggests a closed RE-HC loop between $\mathrm{rRE} \rightarrow \mathrm{CA} 1 \rightarrow \mathrm{Sub} \rightarrow \mathrm{cRE} \rightarrow \mathrm{rRE}$ (Fig. 2A), that may enable RE to modulate the activity level of CA1 cells depending on hippocampal output.

$\mathrm{RE}$ input to the EC has the potential to influence the mPFCEC-HC flow of (spatial and nonspatial/sensory) information, presumably by modulating the excitability level of EC neurons (Fig. $2 \mathrm{~A})$. One study in anesthetized rats has reported excitatory responses in the EC following electrical stimulation of the thalamic midline region (Zhang and Bertram 2002).

A strong RE-mediated feedforward inhibition has been proposed to condition CA1 pyramidal neurons to discharge only under certain circumstances, namely, in the window when inhibition is diminished, and/or when the excitability level of the apical dendrites is further enhanced by other inputs, such as from EC (Dolleman-van der Weel et al. 1997, 2017). In a recent study, Dolleman-van der Weel et al. (2017), showed that low

\section{A}

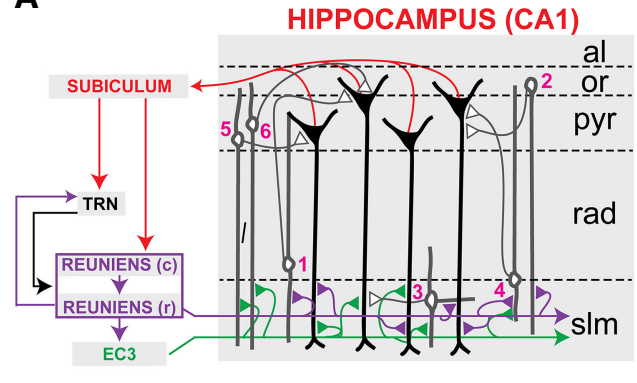

B MEDIAL PREFRONTAL CORTEX

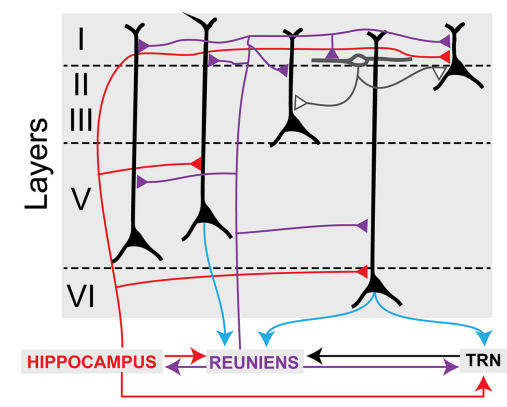

Figure 2. Schematic representation of RE inputs onto excitatory and inhibitory neurons in CA1 and mPFC. (A) Excitatory RE (purple lines) and EC (green lines) inputs in CA1, and a closed CA1 $\rightarrow$ subiculum $\rightarrow R E \rightarrow C A 1$ circuit, including the thalamic reticular nucleus (TRN). The direct $R E \rightarrow C A 1$ input in slm originates from the rostral part of RE; only a minor contribution arises from the caudal part. The output of CA1 (red lines) via the subiculum can be relayed back to caudal RE. In turn, caudal RE projects to rostral RE, which results in a di-synaptic ( $c R E \rightarrow r R E \rightarrow C A 1)$ input in slm, thereby closing a loop. The direct EC $\rightarrow$ CA1 pathway, arising from EC layer III cells, overlaps with the RE input in slm. RE $\rightarrow E C$ input may have the ability to modulate the activity level of EC layer III cells. Electrophysiological data support the view that RE and EC inputs converge (at least partly) onto the same dendritic branch of a pyramidal cell in proximal slm. RE has been shown to drive presumed Schaffer collaterals-associated cells (1) which are thought to inhibit pyramidal cells and other (unidentified) interneurons, and vertical oriens/alveus cells (2), mediating feedforward perisomatic inhibition of CA1 cells. EC is assumed to drive parvalbuminpositive basket cells (5) and chandelier or axo-axonic cells (6) providing feedforward somatic and axonal inhibition, respectively, of pyramidal cells; EC also drives neurogliaform cells in slm (3). RE and EC inputs are proposed to converge on slm-neurogliaform cells (3) providing feedforward inhibition of pyramidal cells and other interneurons in slm, and on a subclass of (presumed CCK/VIP) basket cells (4) located at the slm/radiatum border, providing (peri)somatic inhibition of CA1 cells. (B) mPFC layers 1 and 5/6 contain a high density of RE fibers onto mostly unidentified pyramidal cells and interneurons. They overlap with fibers from CA1/subiculum (red lines); it is not known whether RE and CA1/subiculum inputs convergence onto single neurons in mPFC. RE input drives presumed neurogliaform cells in layer 1 , providing feedforward inhibition of pyramidal cells in layers $2 / 3$ and other unidentified layer 1 interneurons. mPFC (light blue lines) provides direct excitatory input to RE as well as an indirect, presumed inhibitory input via the TRN (black arrow); RE reciprocates the TRN input (purple arrow). Abbreviations: (al) alveus, (c) caudal, (EC3) entorhinal cortex layer III, (or) stratum oriens, (pyr) pyramidal cell layer, $(r)$ rostral, $(\mathrm{rad})$ stratum radiatum, $(\mathrm{slm})$ stratum lacunosum moleculare, $(\mathrm{TRN})$ thalamic 
frequency $(0.1 \mathrm{~Hz})$ paired pulse stimulation of either RE or lateral EC evoked CA1 fEPSPs (subthreshold) with strong homosynaptic PPF, whereas combined stimulation of RE and EC did not support heterosynaptic PPF. Coincident inputs induced a nonlinear enhancement of the elicited field potentials in slm but did not drive pyramidal cells. These data suggest that RE and EC synapses converge on the same dendritic branch of the pyramidal cells. The authors reasoned that the inability to induce CA1 cell firing could be due to persistent inhibitory influences, engaged by either route individually or by their coincidence. RE and EC inputs converge on neurogliaform cells in slm (Fig. 2A, cell 3), as well as on a subclass of cholecystokinin/vasoactive intestinal polypeptidepositive $\left(\mathrm{CCK}^{+} / \mathrm{VIP}^{+}\right)$basket cells located at the radiatum/slm border (Fig. 2A, cell 4) mediating additional perisomatic inhibition (Dolleman-van der Weel et al. 1997, 2017; Chittajallu et al. 2017). The coincident RE-EC induced perisomatic inhibition may modulate input-timing-dependent-plasticity (Dudman et al. 2007), among other inhibitory dynamics in CA1, gating computational activity.

Electrophysiological studies of RE input in the MPFC are limited. Extracellular recordings, reflecting RE-mediated glutamate release onto mPFC neurons (Pirot et al. 1994; Hur and Zaborsky 2005), indicate direct excitatory and indirect inhibitory components (Viana Di Prisco and Vertes 2006; Eleore et al. 2011; Cruikshank et al. 2012). It is assumed that, similar to the $\mathrm{RE} \rightarrow$ CA1 pathway, both pyramidal cells and interneurons in mPFC receive RE input. Low frequency $(0.1 \mathrm{~Hz})$ paired-pulse stimulation of $\mathrm{RE}$ resulted in strong PPF in $\mathrm{mPFC}$ (PL/IL), similar to CA1 (Dolleman-van der Weel et al. 1997, 2017; Viana Di Prisco and Vertes 2006; Eleore et al. 2011). RE also appears unable to evoke action potentials in mPFC principal cells, with the strong caveat that these recordings have been performed in anesthetized animals. Using an optogenetic strategy, Cruikshank et al. (2012) found that activating matrix thalamo-cortical projection neurons, including RE cells, excited mPFC (PL) layer 1 inhibitory neurons, presumably neurogliaform cells (e.g., Overstreet-Wadiche and McBain 2015). In turn, this conveyed feedforward inhibition to pyramidal cells in layers $2 / 3$ as well as other layer 1 interneurons (Fig. 2B). The thalamic-induced inhibition of the latter interneurons likely has a disinhibitory effect on postsynaptic targets. Speculatively, RE-induced feedforward inhibition may impose a narrow temporal window for exciting mPFC pyramidal cells via direct $\mathrm{RE} \rightarrow \mathrm{mPFC}$, and $\mathrm{RE} \rightarrow \mathrm{CA} 1$, and/or CA1 $\rightarrow$ mPFC pathways, thereby facilitating the (timing of) communication between HC and mPFC.

Though the effects of mPFC inputs on RE neurons are not well known, a recent study investigated the influence of $\mathrm{mPFC}$ input on spontaneously active RE neurons in anesthetized rats (Zimmerman and Grace 2018) using extracellular single-unit recordings in RE and manipulated activity in the infralimbic prefrontal area (IL). The results showed that (1) following tetrodotoxin (TTX) inactivation of IL neurons RE burst firing was reduced, (2) following inhibition of the $\mathrm{mPFC}(\mathrm{IL}) \rightarrow \mathrm{RE}$ pathway utilizing the projectionspecific approach with DREADDs (designer receptors exclusively activated by designer drugs), a subset (40\%) of the spontaneously active RE neurons showed an enhancement of burst firing without an increase in number of spikes, and (3) acute electrical $(0.5 \mathrm{~Hz})$ stimulation of mPFC (IL) resulted in complex responses in $75 \%$ of RE neurons. That is, while only eight RE neurons from three different rats were recorded, six of these cells initially stopped (tonic) firing, followed by rebound spiking (mostly bursting), and after 15-25 stimuli they stopped firing altogether. Thus, mPFC input to RE appeared to have shifted the firing mode from tonic to burst firing, followed by silence. Zimmerman and Grace (2018) hypothesized that the $\mathrm{mPFC} \rightarrow \mathrm{RE}$ input may entrain bursting in RE neurons, with silencing effects achieved via the $\mathrm{mPFC} \rightarrow \mathrm{TRN} \rightarrow \mathrm{RE}$ pathway (Fig. 2B). While direct mPFC-RE input is glutamatergic, feedforward inhibition of RE occurs via GABAergic input from the TRN (Halassa and Acsády 2016). Muscimol inhibition of TRN, had no effects on the spontaneous firing rate, bursting or spike counts in RE cells, but it did reduce the number of spontaneously active cells (Zimmerman and Grace 2018). These results, although puzzling, indicate distinct roles of the TRN $\rightarrow \mathrm{RE}$, and $\mathrm{mPFC}(\mathrm{IL}) \rightarrow \mathrm{TRN} \rightarrow$ RE pathways.

\section{Role of RE in oscillations and synchronization}

Several studies, not reviewed here, show that the interactions of the $\mathrm{mPFC}$ and $\mathrm{HC}$ are critical to cognition. It is commonly speculated that RE promotes these interactions, possibly through synchronization of slow, gamma, and/or theta frequency oscillations that facilitates communication.

The physiological properties of RE neurons (Jankowski et al. 2014, 2015; Lara-Vásquez et al. 2016; Walsh et al. 2017; Zimmerman and Grace 2018) appear supportive of a significant involvement of RE-CA1/subiculum and RE-EC projecting neurons in very slow oscillations $(0.1-1 \mathrm{~Hz})$. This is in line with electrophysiological results (Dolleman-van der Weel et al. 1997, 2017), showing that low $(\leq 2 \mathrm{~Hz})$ frequency stimulation of RE yielded much larger amplitude CA1 fEPSPs than following stimulation at theta frequencies $(4-10 \mathrm{~Hz})$. Moreover, RE is thought to impose a slow oscillation on CA1 pyramidal cells through synapses on inhibitory neurons (Dolleman-van der Weel et al. 1997; Zhang et al. 2012; Duan et al. 2015). Xu and Südhof (2013) proposed that by facilitating the EC input during hippocampal slow oscillations, RE may contribute to the neocortical-hippocampal dialogue and subsequent memory consolidation, an idea that is supported by recent electrophysiological findings (Dolleman-van der Weel et al. 2017). Furthermore, behavioral studies have shown that RE is involved in (hippocampal-dependent) memory consolidation (e.g., Loureiro et al. 2012), a process dependent on slow $(<1 \mathrm{~Hz})$ synchronized oscillations in mPFC and HC (Huber et al. 2004; Mölle and Born 2011).

The long-range synchronization of gamma may enable communication between distant brain regions (e.g., Fries 2015). Ferraris et al. (2018) recently provided evidence that RE serves to synchronize bursts of gamma activity in CA1 and mPFC (PL). During slow oscillations synchronized gamma bursts $(30-90 \mathrm{~Hz})$ occur in the mPFC and HC in adult rats under anesthesia and natural sleep (Ferraris et al. 2018). Both CA1 and mPFC cells were entrained by the gamma oscillations, but they did not participate in the actual synchronization of CA1 and mPFC gamma bursts. Instead, RE neurons appeared related and increased their firing prior to the synchronized gamma burst onsets, while muscimol inactivation of RE disrupted synchronization of the CA1 and mPFC gamma bursts. The authors suggested that RE may actively promote/drive the mPFC-HC gamma burst coupling during slow oscillations, thereby providing a temporal window for information exchange/memory consolidation during slow wave sleep (Ferraris et al. 2018).

Synchronized prefrontal-hippocampal activity in the theta range $(4-10 \mathrm{~Hz})$ occurs predominantly during exploration and REM sleep and is related to several learning and memory processes (Boyce et al. 2016; Guise and Shapiro 2017). Whether RE plays an important role in driving hippocampal theta waves, and/or in theta coupling between $\mathrm{mPFC}$ and $\mathrm{HC}$ is unclear from the available data. For example, during rat neonatal development the mPFC$\mathrm{RE}$ connectivity is involved in theta band coupling of $\mathrm{MPFC}$ and $\mathrm{HC}$, providing an early transthalamic feedback mechanism for mPFC control over CA1 activity (Hartung et al. 2016).

Additionally, RE contains a small percentage of neurons with various spatial properties, i.e., head direction cells, "place cells" 
with low levels of spatial information, and perimeter/border or boundary cells (Jankowski et al. 2014, 2015). In freely moving rats these cells display firing properties in the theta range, however coherence with hippocampal theta oscillations is low. RE cells display trajectory-dependent activity in a continuous alternation task, phase-locked to theta rhythm in CA1 (Ito et al. 2015). Recently, Ito et al. (2018) reported that firing of mPFC and RE neurons show enhanced coordination with the CA1 theta rhythm when rats approached the choice point in a T-maze. However, the temporal coordination in mPFC-RE-CA1 seemed dependent on the supramammillary nucleus (SUM) determined by optogenetic silencing.

In anesthetized rats, however, various reports have indicated that RE has little effect on hippocampal theta. For instance, RE is likely not involved in atropine-resistant theta (Vanderwolf et al. 1985), and RE spiking activity during spontaneous or tail-pinch induced hippocampal theta oscillations displayed only a very low coherence with hippocampal theta (Morales et al. 2007). In addition, low frequency $(0.1-2 \mathrm{~Hz})$ electrical stimulation of RE may disrupt spontaneously occurring hippocampal theta oscillations, even up to a point of near complete suppression (Dolleman-van der Weel, unpublished observations).

There are some contrasting results on theta coupling between $\mathrm{mPFC}$ and HC. On the one hand, lidocaine inactivation of RE resulted in a decreased coherence between $2-5 \mathrm{~Hz}$ delta oscillations in $\mathrm{mPFC}$ (PL) and HC, but had minimal effect on coupling at theta frequencies (Roy et al. 2017). On the other hand, an N-methylD-aspartate (NMDA) lesion of RE impaired the coherence of mPFC-HC (PL-CA1) theta (and beta) frequency oscillations (Kafetzopoulos et al. 2018). Interregional synchronization in the dorsal CA1-RE-mPFC direction was also observed. Using a spatial working memory (SWM)-dependent delayed alternation (DA) task Hallock et al. (2016) showed that RE inactivation robustly decreased the proportion of mPFC neurons that were phase-locked to hippocampal theta during delay periods of the SWM task.

In summary, electrophysiological data indicate that RE can modulate neuronal activities in MPFC and HC through a complex interplay of direct excitatory effects on principal cells and subclasses of local inhibitory interneurons. Thus, RE may exert a (statedependent) influence on the excitation/inhibition balance and level of plasticity. In addition, through activation of interneurons RE may impose an oscillatory rhythm on pyramidal cell ensembles that facilitates the local and interregional flow of information. Whether the latter involves the collateralized RE projections to CA1 and $\mathrm{mPFC}$ is as yet an unresolved issue. Return projections to RE, i.e., the direct mPFC-RE and indirect mPFC-TRN-RE pathways, are tentatively proposed to have distinct effects on firing mode of RE neurons.

\section{Potential RE circuit dynamics}

The anatomy and physiology of RE presents an emerging picture of an extensive network that includes the HC, EC, PRC, mPFC, and TRN involving a complex interplay of state-dependent excitatory/inhibitory effects on neuronal activity that occurs both locally and at the circuit/network level. Here we attempt to coalesce and simplify RE functions in a model based on the conceptualization of RE as a canonical, higher-order, cortico-thalamo-cortical circuit (Theyel et al. 2010; Sherman, 2017) situated at the nexus of the mPFC and HC. By modulating specific, temporally coherent patterns of neuronal activity, RE organizes interactions between an anatomically extended set of diencephalic, mPFC, and medial temporal lobe circuits-distributed coalitions that are required for the highest orders of cognition involving the integration of memory, motivation, and actions directed by expected outcomes. Though the model incorporates several key anatomical and physiological features of RE circuitry, many details remain unknown, and our description is intended as a framework for further investigating RE circuit function. The model emphasizes integration and coordination functions of RE with respect to three levels of organization: anatomical connectivity, neuronal modulation, and computational process (depicted in Fig. 3). At a fundamental level RE neurons must act as integrators based on their massive inputs and limited outputs (see above anatomy). This input-output ratio likely implements a form of dimensionality reduction resolving appropriate features of information within the context of frontotemporal interactions, and influenced by the many inputs from regions associated with diverse behavioral and autonomic states. Likewise, the central location of RE positions it to coordinate activity throughout the mPFC-RE-HC system leading to the idea that RE serves a critical a role in synchronization, gating, and inhibitory control.

In the conceptual model, we enumerate seven possible RE mechanisms: (1) RE could coordinate coherent interactions across mPFC-RE-HC through the $5 \%-10 \%$ of RE-CA1 projecting cells with collateralized axons to both mPFC and the HC (e.g., Hoover and Vertes 2012; Varela et al. 2014). As reviewed above, there are some indications for this role (e.g., Hallock et al. 2016; Roy et al. 2017), but direct evidence is lacking. Coordination could include delta and theta frequency bands, slow oscillations and/or coupling of these with higher frequency bands such as gamma. (2) RE cells could coordinate and integrate its vastly distributed afferents with specific inputs originating from $\mathrm{mPFC}$, extract central features such as goal trajectory (Ito et al. 2015), and project this information onto the HC. This, in turn, might drive neuronal activation sequences related to situation appropriate memory acquisition or retrieval states in HC. (3) RE cells could coordinate and integrate its vast afferents with specific input originating in the HC, extract common features such as situation appropriate contextual representations (as opposed to detailed representations), and project this information onto mPFC. These inputs to mPFC might drive memory-based cognitive and behavioral control mechanisms. The latter two functions would be similar to other cortico-thalamocortical pathways where the thalamus has been shown to transfer information (e.g., Theyel et al. 2010). (4) RE cells could provide the mechanism for cortico-thalamic gating and/or, (5) subiculothalamic gating, via feedforward inhibitory inputs from the TRN neurons (Çavdar et al. 2008). Such TRN-based gating could enable $\mathrm{RE}$ cells to modulate the directional route of flow from $\mathrm{mPFC} \rightarrow \mathrm{RE}$ $\rightarrow \mathrm{HC}$ or $\mathrm{HC} \rightarrow \mathrm{RE} \rightarrow \mathrm{mPFC}$ on fundamental neural integration and processing time scales (tens of milliseconds). Such a mechanism could allow for rapid informational loops updating increasingly advanced representations relevant to ongoing memory-guided behavior. Generally, this type of feedforward gating mechanism provides for rapid transitions between large cognitive networks via the thalamus. (6) $\mathrm{RE} \rightarrow$ mPFC projections might drive both inhibitory and principal neurons providing computational control over cognitive states within the mPFC. (7) $\mathrm{RE} \rightarrow \mathrm{HC}$ projections could drive both inhibitory and principal neurons with its massive inputs to slm, but this excitatory input may not drive action potentials in pyramidal cells directly (Dolleman-van der Weel et al. 1997; Chittajallu et al. 2017). Instead, RE inputs might serve to alter the computational state of CA1, affecting encoding, consolidation and memory retrieval (e.g., Xu and Südhof 2013). For example, RE inputs may tune the magnitude and timing of network excitability reflected in local field potential oscillations. Such modulation would strongly affect synaptic integration, action potential generation, and plasticity mechanisms.

While this conceptual model is neither exhaustive nor validated, it provides a simple framework for hypothesis-driven work on the role of the RE in cognitive neurobiology by considering circuit dynamics. The basic idea is that the mPFC and $\mathrm{HC}$ is an 


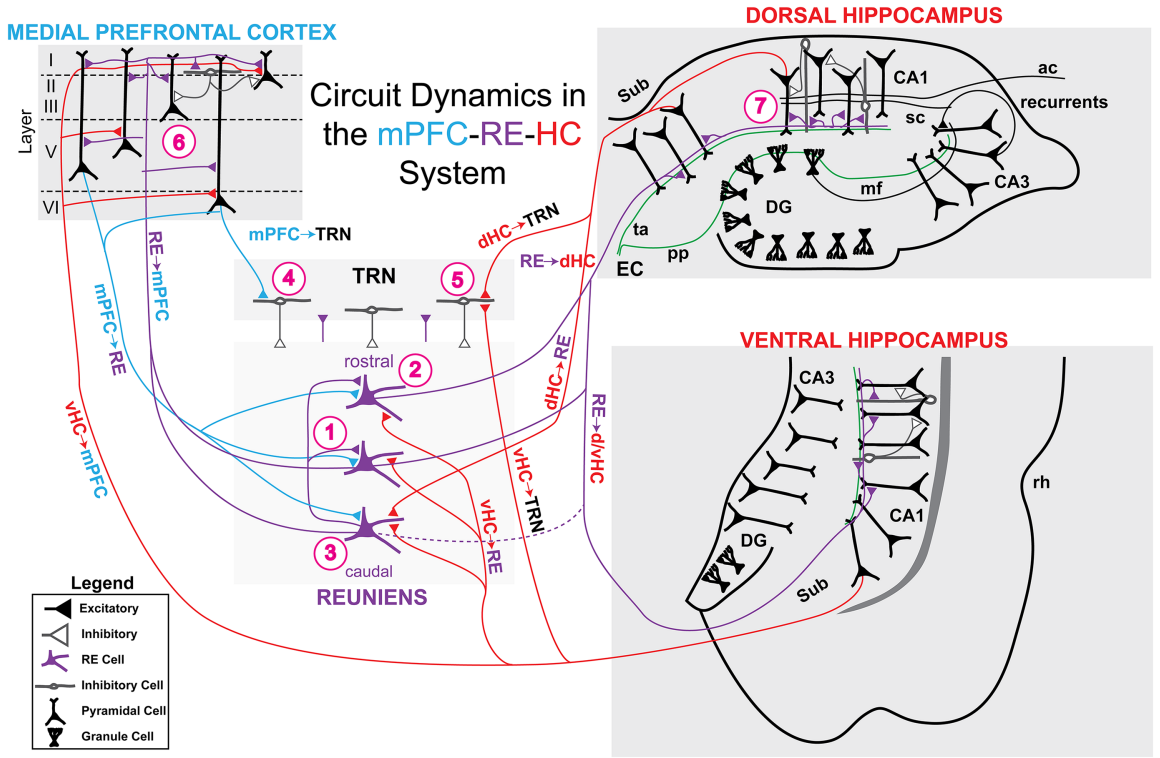

Figure 3. Conceptual model of circuit dynamics in the mPFC-RE-HC system. Note that both the dorsal and ventral $\mathrm{HC}$ are depicted to emphasize these divisions. The model is focused on RE neurons (purple) with projections (dense, solid purple line; light, stippled purple line) to HC, mPFC, other RE neurons, and TRN. In turn, RE neurons receive input from HC (red), mPFC (blue), and TRN (dark gray). Throughout the model, inhibitory cells have a white soma and white triangle synapses; excitatory cells have black somas and colored triangle synapses. The model proposes seven potential circuit mechanisms: (1) mPFC-RE-HC synchronization might be achieved through the small subpopulation of RE neurons with collateralized axons to both $\mathrm{mPFC}$ and $\mathrm{HC}$. (2) $\mathrm{mPFC} \rightarrow \mathrm{RE} \rightarrow \mathrm{HC}$ integration and propagation through $\mathrm{RE}$ neurons and (predominantly rostral) $\mathrm{RE} \rightarrow \mathrm{HC}$ projections. There is the potential for additional integration/modulation of rostral RE neurons via inputs from ventral subiculum and caudal RE neurons. (3) HC $\rightarrow \mathrm{RE} \rightarrow \mathrm{mPFC}$ integration and propagation through a subpopulation of caudal RE neurons that receive (dorsal and ventral) subicular afferents, and project to mPFC. (4) Cortico-thalamic gating through $\mathrm{mPFC} \rightarrow$ TRN projections, and (5) Subiculo-thalamic gating through $\mathrm{d} / \mathrm{v}$ Subiculum $\rightarrow$ TRN projections, both providing feedforward inhibition on RE, or other thalamic nuclei. (6) RE $\rightarrow$ mPFC projections could modulate/drive the computational state of $\mathrm{MPFC}$ through excitatory inputs onto pyramidal cells, and on inhibitory interneurons in layer 1. (7) $\mathrm{RE} \rightarrow \mathrm{HC}$ projections could modulate/drive the computational state of CA1 through excitatory inputs onto pyramidal cells, and inhibitory interneurons, colocalized with EC layer III inputs in slm. Each of these circuit mechanisms could serve several functions in memory and behavior, but each needs to be tested in empirical studies using techniques able to isolate circuit-level mechanisms, such as optogenetics and DREADD based experiments in freely behaving animals. Abbreviations: (dHC) dorsal hippocampus, (CA1) cornu ammonis field 1, (DG) dentate gyrus, $(\mathrm{HC})$ hippocampus, (mf) mossy fibers, (mPFC) medial prefrontal cortex, (pp) performant path, (rh) rhinal sulcus, (RE) nucleus reuniens of the thalamus, (sc) Schaffer collateral, (slm) stratum lacunosum moleculare, (Sub) subiculum, (ta) temporoammic pathway, (TRN) thalamic reticular nucleus, (vHC) ventral hippocampus.

instantiation of a canonical cortico-thalamo-cortical circuit in the brain capable of bridging the memory and executive systems.

\section{Behavioral functions of RE}

In this section, we review the role of RE in navigation, spatial working memory, the temporal organization of memory, and executive functions. RE contributions to these tasks have been studied using lesions (e.g., electrolytic or NMDA), pharmacological inactivation (e.g., muscimol), circuit-specific approaches (e.g., optogenetics and DREADDs), and in vivo electrophysiolgical approaches (e.g., fine-wire tetrodes). Each approach has caveats for use in studying $\mathrm{RE}$, the most obvious of which is that RE is difficult to target because it is deep and on the midline. Additionally, NMDA lesions may cause epileptic activity in CA1 (Hirayasu and Wada 1992), muscimol may spread to nearby thalamic regions and affect motor behaviors (e.g., Starr and Summerhayes 1983; Klockgether et al. 1985), and recordings in RE are difficult to localize in vivo due to a lack of an established electrophysiological signature. Regardless, careful application of these approaches has led to the overarching conclusion that RE is critical to learning and memory, and involved in executive functioning.

\section{RE in spatial navigation}

Spatial navigation is an essential ability for animals living in space. Although individual animal species appear to develop different navigation strategies, a key feature of rats (and humans) is their strategy based on internal maps in the brain (Tolman, 1948; O'Keefe and Nadel 1978). This map-based navigation eliminates the necessity to memorize sequences of individual movements toward goals. Instead, the extraction of geometric relationships between spatial landmarks allows animals to plan routes to various destinations flexibly. In support of this idea, studies have identified neurons that fire depending on the animal's position in space, such as place cells or grid cells (O'Keefe and Dostrovsky 1971; Hafting et al. 2005). However, it is still largely unknown how other cortical structures use such geometric relationships to plan a route, or action sequences, toward destinations.

The mPFC has been considered a key structure for navigation. For example, lesioning mPFC impaired flexible planning of route from different start positions to the goal (Granon and Poucet 1995). Furthermore, goal-directed navigation was impaired in a human patient with damage in the ventral mPFC (Ciaramelli 2008; Spiers 2008). Notably, the patient was able to navigate successfully if the goal location was repeated periodically, suggesting $\mathrm{mPFC}$ may play a role in goal representation and route planning during navigation. Consistent with this idea, studies have reported the temporal coordination of activity between $\mathrm{mPFC}$ and $\mathrm{HC}$ during navigation. When the animal makes a decision about the next route at a T-junction of a maze, the spectral coherence between $\mathrm{mPFC}$ and $\mathrm{HC}$ is modulated in the theta-frequency band (Benchenane et al. 2010). At the cellular level, mPFC spiking becomes phase-locked to theta oscillations in HC (Jones and Wilson 2005; Siapas et al. 2005; Ito et al. 2018). This behavior dependent spike-time coordination implies dynamic functional coupling between mPFC and HC during routing.

While previous studies indicate a key role for mPFC-HC interactions in navigation, the origin of the axonal projection in $\mathrm{mPFC}$ from $\mathrm{HC}$ is largely limited to its ventral and intermediate portion (Jay and Witter 1991; Hoover and Vertes 2007), in spite of a pivotal role of dorsal HC in fine-scale spatial representations and spatial learning (Nadel 1968; Moser et al. 1993; Sargolini et al. 2006). The absence of a direct projection from $\mathrm{mPFC}$ to HC leads to a question of how the mPFC-HC communicates in support of navigation. As reviewed above, RE may serve as the primary hub between mPFC and HC (Vertes et al. 2007), and thus navigational behavior may involve the mPFC-RE-HC system. 
One line of evidence for a role of RE in mPFC-HC interactions in memory was provided by Xu and Südhof (2013). They demonstrated that the mPFC-RE-CA1 circuit plays a key role in balancing the specificity and generalization of contextual representations in a fear conditioning task. The results of this study suggest that a RE-mediated circuit may directly influence place cell firing in HC because similarities and differences between environments are thought to be represented by field locations and firing rates across a place cell population (Anderson and Jeffery 2003; Leutgeb et al. 2005; Colgin et al. 2008). Consistent with this notion, Cholvin et al. (2018) recently reported that RE lesions impaired the stability and firing-rate modulation of place cells, which may ultimately influence spatial cognition.

What kind of information is represented in RE neurons? Jankowski and colleagues showed that a subpopulation of RE neurons exhibited a tuning to the animal's head direction or position (Jankowski et al. 2014, 2015), likely reflecting anatomical inputs from the subiculum and parahippocampal region to RE (McKenna and Vertes 2004). A key role of RE in navigation was investigated by Ito and colleagues (Fig. 4; Ito et al. 2015). They recorded the activity of neurons in $\mathrm{mPFC}, \mathrm{RE}$, and CA1 as rats performed a continuous alternation task in a T-maze. The study found that many neurons in RE or mPFC lack any notable tuning to the animal's position in space during navigation, which contrasts with neurons in HC. However, neurons in RE and $\mathrm{mPFC}$ change firing rates depending on the animal's next movement (either a right or left turn at the T-junction). This trajectory-dependent activity in RE neurons influenced the peak firing rates of place cells in the hippocampal CA1, which otherwise retained their spatially selective firing. While it has long been known that place cells change their activity depending on the animal's trajectory (Markus et al. 1995; Frank et al. 2000; Wood et al. 2000), such modulation is likely mediated by the $\mathrm{mPFC} \rightarrow \mathrm{RE}$ circuit. Consistent with this notion, the trajectory-dependent rate change of place cells was largely diminished by lesions or by optogenetic-silencing of RE (Ito et al. 2015).

The functional investigation of RE further elucidated a role for theta-rhythm spike-time coordination in mPFC-HC interactions. When the animal decides the next route at the T-junction, neurons in $\mathrm{mPFC}$ and RE enhance their spike-time coordination with the HC theta rhythm, resulting in efficient transfer of trajectory information from mPFC to HC (Ito et al. 2018). Interestingly, this spike-time coordination in the mPFC-RE-CA1 circuit was mediated by SUM in the hypothalamus that projects to mPFC, RE, and HC (Vertes 1992; Pan and McNaughton 2004), pointing also to subcortical structures as key nodes for controlling mPFC-HC interactions.
A

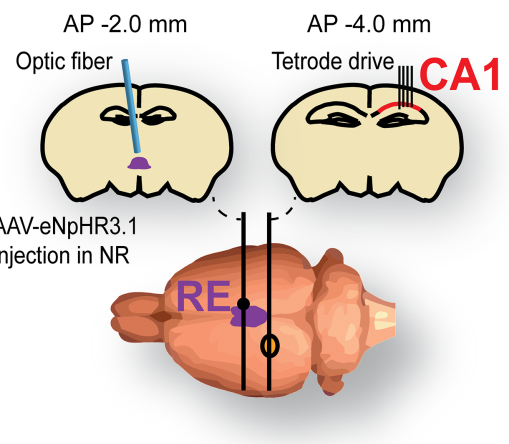

B
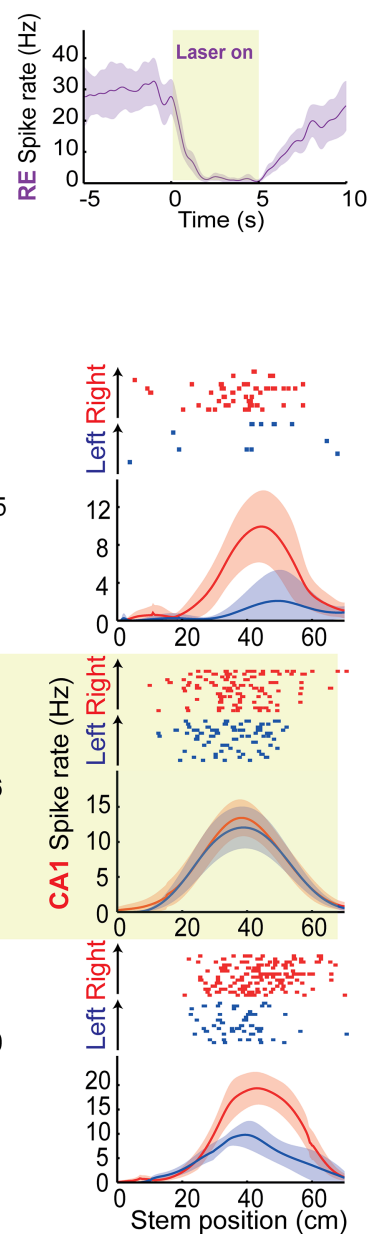

Figure 4. Trajectory-dependent coding in CA1 depends on RE activity. $(A)$ Rats were implanted with an optical fiber targeting RE with RE cells expressing the enhanced halorhodopsin eNpHR3.1. Recordings were made from tetrodes implanted in dorsal CA1 while rats performed a continuous alter(C) A sample CA1 neuron shown before, during, and after RE silencing. Under control (before and after) conditions, the CA1 neuron shows trajectory-dependent coding with more firing on the stem of the maze for right-bound runs. During RE inactivation trajectory-dependent coding is diminished. Abbreviations: (CA1) cornu ammonis field 1, (RE) nucleus reuniens of the thalamus. Reprinted from Ito et al. (2015) with permission.
While these studies indicate the role of RE in transferring information about the animal's next movement from mPFC to the $\mathrm{HC}$, why is such information necessary in HC? The exact contribution of the RE-mediated information is unclear because lesions or inactivation of RE impairs the animal's performance in some navigation tasks (Cholvin et al. 2013; Mei et al. 2018), but not in others such as a simple alternation task or water-maze task (Dolleman-van der Weel et al. 2009; Ito et al. 2015). However, several hints are available. One study demonstrated that neurons in $\mathrm{MPFC}$ and RE represent the movement directions in a selfcentered, or egocentric, perspective (Ito et al. 2015). However, during navigation, each intended movement must be evaluated based on the animal's position and head direction in the environment, information primarily represented in HC and parahippocampal structures (Moser et al. 2008, 2014). The mPFC-RE-CA1 circuit may therefore mediate the integration of egocentric action plans with a spatial map in the $\mathrm{HC}$, providing a necessary 
computational step to assess the next move based on its geometric relationships to the destination.

\section{RE in spatial working memory}

Working memory is the maintenance of trial-specific information over a brief temporal delay. One example would be remembering the location of your parked car while walking into a store, or holding a phone number in mind before entering it into the contacts on your phone. Recent research into the neurobiological basis of SWM has focused on the mPFC-RE-HC system.

Most experimental SWM tasks involve alternations in a T-maze. As discussed above, the simplest variant is the continuous alternation (CA) task, in which the rodent runs from the left reward zone to the right reward zone in a figure-eight pattern without stopping (Wood et al. 2000; Lee et al. 2006; Ainge et al. 2007), with performance dependent on memory for the previous run in order to successfully alternate. In DA task versions, working memory demand is increased by having animals stop during a given time delay (seconds or minutes) before the next alternation can be made. Control tasks include all the same demands, but do not require the stimuli to be held in mind for successful performance. For example, the tactile-visual conditional discrimination (CD) task (Griffin et al. 2012) used different tactile floor inserts associated to different reward zones (i.e., the right or left side). CD depends on the integrity of the dorsal striatum but not dorsal HC, and the opposite is true for DA (Hallock et al. 2013a). Notably, CD tasks can be modified to make them SWM-dependent. Instead of covering the entire maze with the conditional cue, the cue is only presented at the beginning of the maze stem but absent at the T-junction. mPFC inactivation disrupts choice accuracy on the SWM version of the CD task, but not the SWM-independent version (Shaw et al. 2013).

SWM depends on mPFC-HC functional connectivity. For example, mPFC-HC oscillatory coupling in the $4-12 \mathrm{~Hz}$ (theta) range is prominent during SWM (Jones and Wilson 2005). Additionally, mPFC single neuron entrainment to the HC theta rhythm reflects accuracy on a delayed nonmatch to sample (DNMS) task performed in an operant chamber (Hyman et al. 2010). In agreement with these findings, Hallock et al. (2016) showed that mPFC-HC theta synchrony is strongest under situations in which SWM is required. Specifically, the authors found that theta coherence was significantly higher on DA compared to CD tasks as rats moved through the T-junction of the maze (Hallock et al. 2016). One important modulator of mPFC-dorsal HC theta synchrony is the ventral HC. For example, Spellman et al. (2015) optogenetically inhibited ventral HC terminals in mPFC during different phases of the delay nonmatch to place (DNMP) task in mice. Ventral HC terminal suppression during the sample, but not delay or choice phases, impaired accuracy and interfered with task coding in mPFC single-unit activity. This suggests that ventral HC inputs to mPFC are critical for encoding task-specific spatial information. Additionally, removal of ventral $\mathrm{HC}$ input to mPFC disrupted mPFC-dorsal HC synchrony, suggesting that the direct pathway from ventral $\mathrm{HC} \rightarrow \mathrm{mPFC}$ contributes to $\mathrm{mPFC}$-dorsal HC functional coupling and SWM (O'Neill et al. 2013).

$\mathrm{RE}$ is ideally situated to modulate mPFC-HC interactions in SWM (Vertes et al. 2007). Consistent with this role, inactivation of RE with muscimol impaired performance on the SWM-dependent CD task, but leaves the SWM-independent variant unaffected (Fig. 5; Hallock et al. 2013b). Further as the delay length is increased, the deficits increase (Layfield et al. 2015). Recently, the temporal precision offered by optogenetic techniques was used to suppress RE during the sample, delay, and choice phase of a DNMP task (Maisson et al. 2018). Results showed that optogenetic suppression of the RE during the sample phase, but not the delay or choice phases, impairs choice accuracy. Together with Spellman et al. (2015), these findings suggest that both RE and ventral HC input to MPFC are critical for encoding task-relevant information during SWM.

Another recent study answered a more mechanistic question of how RE might affect the mPFC-HC circuit (Hallock et al. 2016). In the study, RE inactivation was combined with dual-site LFP recordings in $\mathrm{mPFC}$ and dorsal HC. Rats were trained to asymptotic performance on the DA task. Before, during, and after RE inactivation with muscimol LFPs were recorded from $\mathrm{mPFC}$ and dorsal HC while DA trials were run. RE inactivation significantly impaired DA choice accuracy which was also accompanied by a reduction in mPFC-dorsal HC coherence.

Overall, these studies show that RE is critical for both SWM and mPFC-HC synchrony. However, many questions remain about how RE modulates SWM. For example, is the dependence on RE due solely to its role in synchronizing theta oscillations between $\mathrm{mPFC}$ and HC? What is the impact of RE inputs to $\mathrm{mPFC}$, $\mathrm{HC}$, and EC at different times during SWM? Exploring these, and other, circuit-level questions will be critical to understanding how and when RE contributes to SWM.

\section{RE in the temporal organization of memory}

The temporal organization of memory has been studied in a wide array of tasks, and is generally thought to help assemble events into separate episodes (Clayton and Dickinson 1998; Tulving 2002; Kesner and Hunsaker 2010; Jacobs et al. 2013; Eichenbaum 2017). Although many of our experiences occur in the same places (e.g., our lab), with the same items (e.g., our computers), the temporal information is always distinct. That is, information about "when" an event occurred is stored in memory, in addition to "what" occurred and "where" it occurred (Allen and Fortin 2013).

A commonly studied form of the temporal organization of memory is the memory for sequences of events. Memory for sequences of events tasks are thought to model the fundamental flow-of-events aspect of episodic memory (Allen et al. 2014). That is, sequence memory provides a representation of the order of events as they occurred within an experience, and underlies our ability to "play back" experiences. Many studies have shown that memory for sequences of events is dependent on both mPFC and HC (Fortin et al. 2002; Kesner et al. 2002; Hannesson et al. 2004; Knierim et al. 2006; Barker et al. 2007; Ekstrom and Bookheimer 2007; Euston et al. 2007; DeVito and Eichenbaum 2011). Thus, if an essential role of RE is to support mPFC and HC functions, then RE should be critical for remembering sequences.

Although little is known about the role of RE in sequence memory, a recent report tested the hypothesis that RE is critical to remembering sequences of events in rats (Fig. 6; Jayachandran et al. 2018). In this study, rats were trained on an odor-based sequence memory task in which they had to identify odors as "in sequence" or "out of sequence" for water rewards. Notably, the sequence task explicitly controls for spatial variables by presenting all the odors within a sequence in the same nose port, thus extricating performance from a simple spatial interpretation. Importantly, a previous study has shown that the sequence task drives sequential representations in individual CA1 neurons, with spike timing that phase locks to the beta frequency band, and this activity corresponded with accurate memory performance (Allen et al. 2016). To test the role of RE in the task, Jayachandran et al. (2018) used a DREADD-based synaptic silencing approach (Stachniak et al. 2014) to suppress activity in the $\mathrm{mPFC} \rightarrow \mathrm{RE}$ projection prior to sequence memory testing in well-trained rats (memory was tested, not learning). Local infusions of clozapine 
A Working Memory-Dependent Conditional Discrimination (CDWM)
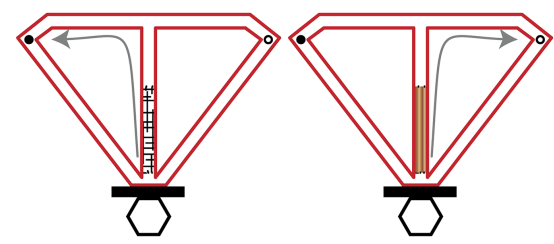

B Working Memory-Independent Conditional Discrimination (CD)

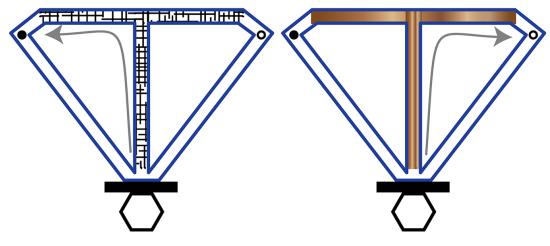

C

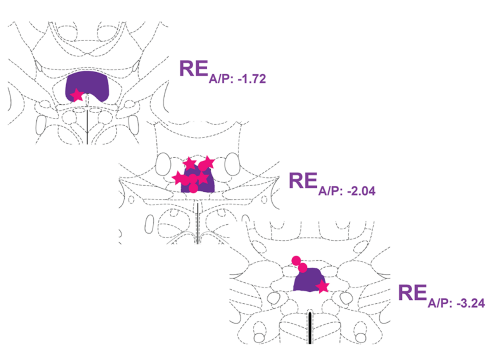

D

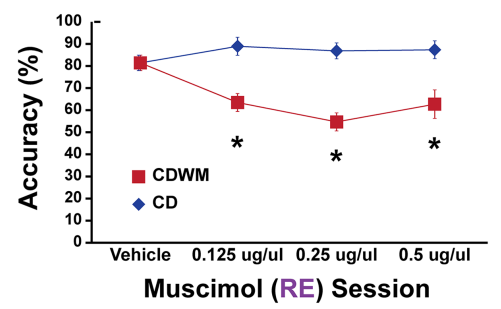

Figure 5. RE is critical for working memory in a T-maze. (A) A working memory-dependent conditional discrimination (CDWM) task was used in which a texture floor insert determined the availability of reward in the left or right reward zone (open/closed circles). However, the texture only covered the first half of the stem and was not present at the T-junction (the choice point) and thus successful performance required working memory. (B) A working memory-independent conditional discrimination (CD) task was used as a control in which all the same task demands were present, except working memory was not required because the floor insert covered the whole stem and T-junction. (C) Prior to testing, the $\mathrm{GABA}_{A}$-agonist muscimol was administered into the RE through a chronically implanted cannula. Cannula tip locations are depicted with pink circles for the CDWM task, and pink stars for the CD task. (D) Compared to vehicle infusion, $\mathrm{RE}$ inactivation with muscimol impaired performance on the CDWM task, but not the CD task, demonstrating a critical role for RE in working memory. Abbreviations: (RE) nucleus reuniens of the thalamus. Reprinted from Hallock et al. (2013b) with permission.

N-oxide (activating hM4Di receptors on presynaptic terminals from $\mathrm{mPFC}$ ) were made directly into RE through cannulas. The results showed that silencing the $\mathrm{mPFC} \rightarrow \mathrm{RE}$ projection repeatedly and effectively abolished sequence memory in rats, but that silencing the $\mathrm{mPFC} \rightarrow \mathrm{RE}$ pathway did not affect running speed, odor sampling, reward retrieval, or nose poke times. An analysis of the distribution of nose poke times reinforced the conclusion that the effect of silencing the $\mathrm{mPFC} \rightarrow \mathrm{RE}$ projections is to reduce the accuracy of sequence memory decisions, rather than change the distribution of reaction times.

Through a detailed lag analysis, Jayachandran et al. (2018) revealed a pattern of deficits that resembled a reduction in a working memory retrieval strategy after silencing the $\mathrm{mPFC} \rightarrow \mathrm{RE}$ pathway, in contrast to a temporal context memory retrieval strategy, which was instead impaired by silencing $\mathrm{mPFC} \rightarrow$ PRC. To clarify this issue, temporal context memory in the sequence task refers to the retrieval gradients that are observed in human studies of list learning (e.g., Howard and Kahana 2002; Kragel et al. 2015). When items are recalled from the list, people will tend to remember the nearby items (short lags), but they are less likely to recall distal items (longer lags). Because verbal recall cannot be performed by animals, the sequence task models list learning using a nonverbal response to probe memory (in and out of sequence decisions). Temporal context memory is demonstrated in this task with a lag analysis in which the retrieval of nearby items interferes with out of sequence decisions but distal items do not. In this same task, working memory is simultaneously tested on reverse lags because delay-matchto-sample strategies can contribute to successful performance. That is, in contrast to temporal context memory, working memory helps reject nearby items but does this less well for distal items (the opposite pattern). The $\mathrm{mPFC} \rightarrow \mathrm{RE}$ silencing effect on working memory retrieval during memory for sequences of events is gener- ally consistent with the role of RE in SWM tasks (e.g., Hembrook et al. 2012; Cassel et al. 2013; Hallock et al. 2013b; Griffin 2015; Viena et al. 2018), and, from a retrieval standpoint, similar to the role of RE in hippocampal-dependent contextual fear memory (Ramanathan et al. 2018). Though more work needs to be done to test the role of RE in a variety of temporal tasks, these early findings suggest that the cognitive role of RE is not restricted to processing spatial variables, but rather RE influences multiple memory functions that likely contribute to episodic memory.

\section{RE in executive functions}

As discussed above, it is now fairly well established that RE directly participates in memory but considerably less attention has been paid to the role of RE in "executive functions," such as attention, goal directed behavior, or behavioral flexibility. This is despite strong RE connections with the medial and orbital PFC, known to be critical for behavioral regulation (Bannerman et al. 2004; Dalley et al. 2004; Kehagia et al. 2010; Chudasama et al. 2012; Abela and Chudasama 2013; Abela et al. 2013). Regarding executive functions, Dolleman-van der Weel et al. (2009) initially reported that lesions of RE did not impair acquisition or retention of spatial reference memory on a water maze task, but nonetheless led to a maladaptive search strategy which was deemed a PFC deficit. Specifically, on the probe test following acquisition, RE-lesioned rats swam directly to the correct quadrant of the pool but upon not finding the platform, immediately began to search the entire pool for the missing platform. This contrasted with sham-operated controls that persistently searched in the training quadrant of the pool. This very rapid switch in strategies of the RE-rats coupled with a failure to adopt a more efficient strategy was described as a deficiency in strategy shifting, typically seen with alterations of the orbital PFC (Amodeo et al. 2017; Izquierdo 2017). Consistent with this, Prasad et al. (2013) demonstrated that $\mathrm{RE}$ lesions produced premature responding on a 5-choice serial reaction time task (5-CSRTT), whereas other indices such as omitting responses (a measure of attention) were unaffected by the lesions. Premature responding is viewed as a deficit in impulse control and is produced with lesions of IL on the 5-CSRTT task (Chudasama et al. 2003). Cassel and colleagues (see Cholvin et al. 2013) further reported that following RE inactivation, rats were unable to suc-

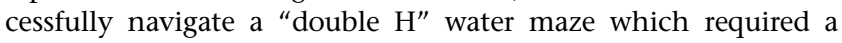
switch in strategy from response to place responding. Linley et al. (2016), using a seven-stage odor/texture discrimination task (Birrell and Brown 2000), found that rats with RE lesions were significantly impaired in reversal learning, indicating an inability to shift to new stimulus-reward contingencies-or behavioral inflexibility. Finally, Viena et al. (2018) recently reported that inactivation of RE with muscimol in rats produced deficits in SWM on a DNMS T-maze task, and additionally resulted in severe perseverative behavior (Fig. 7). Specifically, following incorrect choices on the T-maze, rats were given no-delay correction runs wherein they could immediately choose the correct arm of the maze to retrieve food. Unlike controls, rats infused with muscimol repeatedly 
A

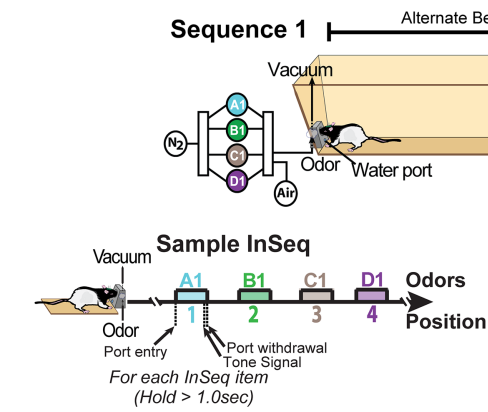

B

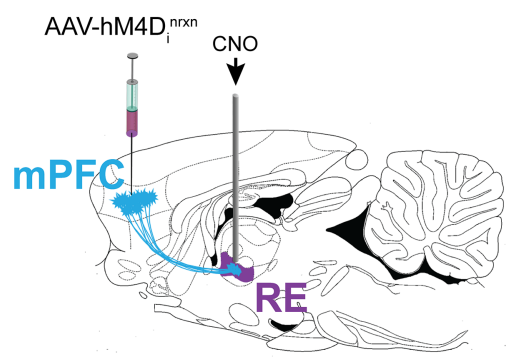

ernate Between Sequences
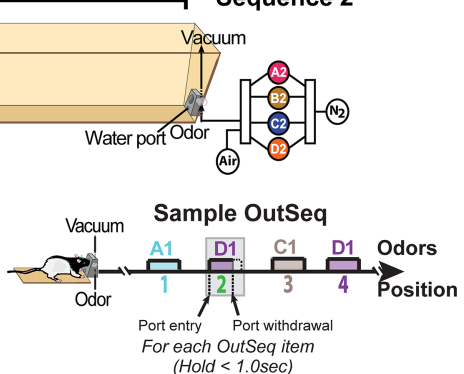

C

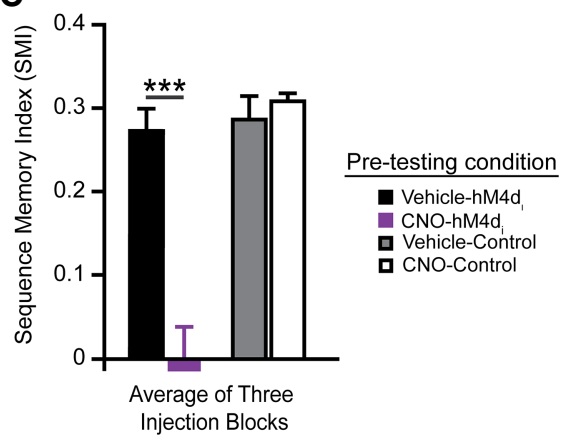

Figure 6. $\mathrm{mPFC} \rightarrow \mathrm{RE}$ projections are critical to memory for sequences of events. $(A)$ Rats were tested on a linear track where two separate four-odor sequences are presented (one sequence on each side). Odor presentations were initiated by a nose-poke, and the rats had to correctly identify the odor as in sequence (hold for $1 \mathrm{sec}$ ) or out of sequence (withdraw prior to $1 \mathrm{sec}$ ). (B) Rats were injected with AAV-hM4D (an inhibitory DREADD) in mPFC or a control virus, and a cannula targeted RE. (C) Well-trained rats were infused with CNO in RE (the DREADD agonist) or vehicle prior to testing. Silencing the $\mathrm{mPFC} \rightarrow$ RE terminals (the $C N O-h M 4 D_{i}$ group) abolished sequence memory, demonstrating that the role for RE is not limited to spatial tasks. Abbreviations: (CNO) clozapine N-oxide, (mPFC) medial prefrontal cortex, (RE) nucleus reuniens of the thalamus. Reprinted from Jayachandran et al. (2018) with permission.

\section{Clinical relevance of RE dysfunction}

Due, in part, to its key position in between the $\mathrm{HC}$ and $\mathrm{mPFC}, \mathrm{RE}$ dysfunction may lead to major clinical problems, such as persistent working memory impairments and other types of cognitive dysfunction shared by many neuropsychiatric disorders (Meyer-Lindenberg et al. 2001, 2005; Lawrie et al. 2002; Bassett et al. 2012; Venkataraman et al. 2012; Argyelan et al. 2014). Although little is known about RE dysfunction, to date, RE has been suggested to be involved in Alzheimer's disease (Braak and Braak 1991; Moretti et al. 2011; Hardenacke et al. 2013), Korsakoff's syndrome (Visser et al. 1999), autism (Ray et al. 2005), stress and depression (Kafetzopoulos et al. 2018), epilepsy (Hirayasu and Wada 1992; Bertram et al. 2001; Graef et al. 2009; Sloan and Bertram 2009; Wang et al. 2009; Drexel et al. 2011), and schizophrenia (Cohen et al. 1998; Lambe et al. 2007; Lisman et al. 2010; Sigurdson et al. 2010; Lisman 2012; Zhang et al. 2012; Saalman 2014; Duan et al. 2015). In Alzheimer's disease, there is a highly specific pattern of neurofibrillary tangles in RE, a pattern that was consistently restricted to those patients with the most severe symptoms (Braak and Braak 1991). In schizophrenia, theta and delta frequency made incorrect choices on the maze in the absence of reward-or showed strong perseverative responding indicative of a lack of behavioral flexibility. Viena et al. (2018) concluded that RE not only serves a role in the SWM but "appears to be a core structure in an extended network mediating executive functioning."

Regarding the network contributing to perseverative behavior (or the inability to switch strategies to changing environmental conditions), the $\mathrm{HC}$ and the orbital PFC appear to serve pivotal roles (for review, see Viena et al. 2018). For instance, Torres-Berrío et al. (2019) recently reported that ventral $\mathrm{HC}$ is critically involved in behavioral flexibility, as TTX-induced inactivation of the ventral HC significantly impaired the ability of rats to switch strategies on a plus maze. As there is limited direct communication between the HC and orbital PFC (Dolleman-van der Weel and Witter 1996; Reep et al. 1996; Vertes et al. 2006, 2007; Hoover and Vertes 2011, 2012), RE appears to be an important link between $\mathrm{HC}$ and orbital PFC as well, possibly serving a vital role in the adaptation to changing environment contingencies.

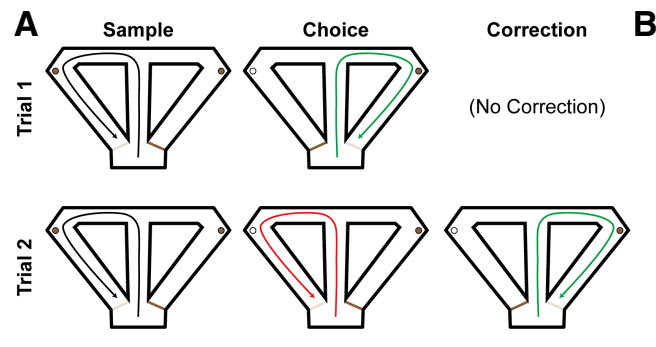

B

C

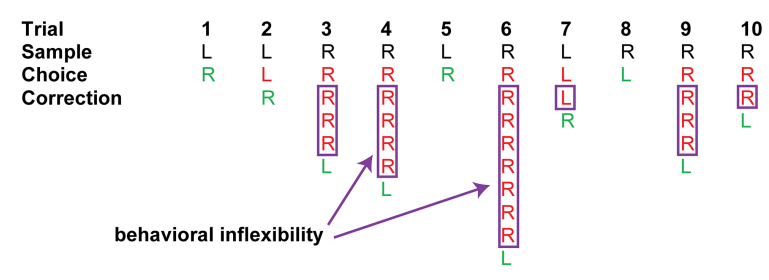

Figure 7. RE inactivation impairs behavioral flexibility. $(A)$ Rats were trained to alternate in a T-maze after a delay, but this version of the task included error correction trials in order to test behavioral flexibility. During the sample phase, rats could choose either side for reward, but next had to choose the opposite side for reward following a delay (standard SWM test). If the rat made the correct choice (green arrow, trial 1) they would move onto the next trial. However, if the rat made a working memory error (red arrow, trial 2) they would be given an immediate opportunity to correct this choice with no delay (the correction phase; green arrow, trial 2). Rats were given repeated correction opportunities until they made the correct response. $(B)$ Prior to testing, rats were infused with the $\mathrm{GABA}_{\mathrm{A}}$-agonist muscimol into RE. (C) RE inactivation impaired SWM, but importantly, also resulted in severe spatial perseveration (repeatedly making the same wrong turn). An example performance following RE inactivation shows many repeated errors on correction runs (purple boxes), suggesting a role for RE in behavioral flexibility. Reprinted from Viena et al. (2018) with permission. 
abnormalities have been specifically attributed to RE dysfunction (Lisman et al. 2010; Lisman 2012; Duan et al. 2015), and the massa intermedia (or interthalamic adhesion) has been frequently reported as absent, or shorter/smaller in schizophrenic patients (e.g., Nopoulos et al. 2001; Ceyhan et al. 2008; Takahashi et al. 2008; Trzesniak et al. 2011, 2012; Landin-Romero et al. 2016). In epilepsy, the hyperexcitability critical for the generation and/or propagation of hippocampal seizure activity (Ang et al. 2006) has been suggested to be due, in part, to the loss of RE-induced feedforward inhibition targeting CA1 (Dolleman-van der Weel et al. 1997, 2017; Dolleman-van der Weel and Witter 2000). This would reflect a RE-HC circuit failure that facilitates a transition from a normal, to a hyperactive, HC-EC loop in limbic epilepsy (Stefan and Lopes da Silva 2013). Altogether these, and other studies, make it very clear that a detailed understanding of RE will importantly shed light on a variety of neurocognitive disorders and in particular why RE dysfunction can be such a detrimental pathological insult.

\section{Conclusions}

The mPFC-RE-HC system, and its complex circuits, are central to memory and executive functions. HC function is needed for people to remember episodes, and selective CA1 lesions cause amnesia (Rempel-Clower et al. 1996). PFC damage does not cause amnesia, but impairs the flexible use of memory especially when recent episodes interfere with one another (Postle 2006). Integrating mPFC and HC requires RE. Although a rich body of anatomical, physiological, and behavioral work has been conducted on RE, the data on $\mathrm{RE}$ are far from complete. It has become increasingly clear that gating the flow of information through CA1 involves highly complex interactions between RE- and EC-mediated excitatory/inhibitory mechanisms, which require further testing. Additionally, the representations and functions of the $\mathrm{HC} \rightarrow \mathrm{mPFC} \rightarrow \mathrm{RE} \rightarrow \mathrm{HC}$ loop appear central to RE function, but few studies have been conducted observing part or all of the loop. Lastly, the role of RE in cognition and behavior likely depends on the activity of specific mPFC-RE-HC pathways and the RE subregion (e.g., rostral/caudal, $\mathrm{RE} /$ periRE) most involved. Thus, future studies on RE will benefit greatly from current advances in genetic and circuit manipulation tools (e.g., optogenetics and DREADDs) that are able to provide the level of specificity needed to rigorously examine detailed aspects of RE circuitry.

\section{Acknowledgments}

We thank Dr. Tatiana Viena for helpful feedback on the manuscript. This work was supported, in part, by NIH grant R01 MH113626 to T.A.A., NIH grant R01 MH102394 to A.L.G., and NIH grant R15 NS108259 to R.P.V. H.T.I. is funded by the Max Planck Society, the Behrens-Weise Foundation, a Starting Grant from the European Research Council ("NavigationCircuits" Grant Agreement no. 714642), and a PRESTO grant from the Japan Science and Technology Agency (JPMJPR1682).

\section{References}

Abela AR, Chudasama Y. 2013. Dissociable contributions of the ventral hippocampus and orbitofrontal cortex to decision-making with delayed or uncertain outcome. Eur J Neurosci 37: 640-647. doi:10.1111/ejn .12071

Abela AR, Dougherty SD, Fagan ED, Hill CJ, Chudasama Y. 2013. Inhibitory control deficits in rats with ventral hippocampal lesions. Cereb Cortex 23: 1396-1409. doi:10.1093/cercor/bhs121

Ainge JA, van der Meer MA, Langston RF, Wood ER. 2007. Exploring the role of context-dependent hippocampal activity in spatial alternation behavior. Hippocampus 17: 988-1002. doi:10.1002/hipo.20301

Allen TA, Fortin NJ. 2013. The evolution of episodic memory. Proc Natl Acad Sci 110: 10379-10386. doi:10.1073/pnas.1301199110
Allen TA, Morris AM, Mattfeld AT, Stark CE, Fortin NJ. 2014. A Sequence of events model of episodic memory shows parallels in rats and humans. Hippocampus 24: 1178-1188. doi:10.1002/hipo.22301

Allen TA, Salz DM, McKenzie S, Fortin NJ. 2016. Nonspatial sequence coding in CA1 neurons. J Neurosci 36: 1547-1563. doi:10.1523/JNEUROSCI .2874-15.2016

Amodeo LR, McMurray MS, Roitman JD. 2017. Orbitofrontal cortex reflects changes in response-outcome contingencies during probabilistic reversal learning. Neuroscience 345: 27-37. doi:10.1016/j.neuroscience .2016.03.034

Anderson MI, Jeffery KJ. 2003. Heterogeneous modulation of place cell firing by changes in context. J Neurosci 23: 8827-8835. doi:10.1523/ JNEUROSCI.23-26-08827.2003

Ang CW, Carlson GC, Coulter DA. 2006. Massive and specific dysregulation of direct cortical input to the hippocampus in temporal lobe epilepsy. $J$ Neurosci 26: 11850-11856. doi:10.1523/JNEUROSCI.2354-06.2006

Arai R, Jacobowitz DM, Deura S. 1994. Distribution of calretinin, calbindin-D28k, and parvalbumin in the rat thalamus. Brain Res Bull 33: 595-614. doi:10.1016/0361-9230(94)90086-8

Argyelan M, Ikuta T, DeRosse P, Braga RJ, Burdick KE, John M, Kingsley PB, Malhotra AK, Szeszko PR. 2014. Resting-state fMRI connectivity impairment in schizophrenia and bipolar disorder. Schizophr Bull 40: 100-110. doi:10.1093/schbul/sbt092

Bannerman DM, Rawlins JN, McHugh SB, Deacon RM, Yee BK, Bast T, Zhang WN, Pothuizen HH, Feldon J. 2004. Regional dissociations within the hippocampus-memory and anxiety. Neurosci Biobehav Rev 28: 273283. doi:10.1016/j.neubiorev.2004.03.004

Barker GR, Bird F, Alexander V, Warburton EC. 2007. Recognition memory for objects, place, and temporal order: a disconnection analysis of the role of medial prefrontal cortex. J Neurosci 27: 2948-2957. doi:10.1523/ JNEUROSCI.5289-06.2007

Bassett DS, Nelson BG, Mueller BA, Camchong J, Lim KO. 2012. Altered resting state complexity in schizophrenia. Neuroimage 59: 2196-2207. doi:10.1016/j.neuroimage.2011.10.002

Baydin S, Gungor A, Baran O, Tanriover N, Rhoton AL. 2016. The double massa intermedia. Surg Neurol Int 7: 30. doi:10.4103/2152-7806.179383

Benchenane K, Peyrache A, Khamassi M, Tierney PL, Gioanni Y, Battaglia FP, Wiener SI. 2010. Coherent $\theta$ oscillations and reorganization of spike timing in the hippocampal-prefrontal network upon learning. Neuron 66: 921-936. doi:10.1016/j.neuron.2010.05.013

Bertram EH, Zhang D. 1999. Thalamic excitation of hippocampal CA1 neurons: a comparison with the effects of CA3 stimulation. Neuroscience 92: 15-26. doi:10.1016/S0306-4522(98)00712-X

Bertram EH, Mangan PS, Zhang D, Scott CA, Williamson JM. 2001. The midline thalamus: alterations and a potential role in limbic epilepsy. Epilepsia 42: 967-978. doi:10.1046/j.1528-1157.2001.042008967.x

Birrell JM, Brown VJ. 2000. Medial frontal cortex mediates perceptual attentional set shifting in the rat. J Neurosci 20: 4320-4324. doi:10.1523/ JNEUROSCI.20-11-04320.2000

Bokor H, Csáki A, Kocsis K, Kiss J. 2002. Cellular architecture of the nucleus reuniens thalami and its putative aspartatergic/glutamatergic projection to the hippocampus and medial septum in the rat. Eur J Neurosci 16: 1227-1239. doi:10.1046/j.1460-9568.2002.02189.x

Boyce R, Glasgow SD, Williams S, Adamantidis A. 2016. Causal evidence for the role of REM sleep $\theta$ rhythm in contextual memory consolidation. Science 352: 812-816. doi:10.1126/science.aad5252

Braak H, Braak E. 1991. Alzheimer's disease affects limbic nuclei of the thalamus. Acta Neuropathol 81: 261-268. doi:10.1007/BF00305867

Cassel JC, Pereira de Vasconcelos A, Loureiro M, Cholvin T, Dalrymple-Alford JC, Vertes RP. 2013. The reuniens and rhomboid nuclei: neuroanatomy, electrophysiological characteristics and behavioral implications. Prog Neurobiol 111: 34-52. doi:10.1016/j .pneurobio.2013.08.006

Çavdar S, Onat FY, Çakmak YO, Yananli HR, Gülçebi M, Aker R. 2008. The pathways connecting the hippocampal formation, the thalamic reuniens nucleus and the thalamic reticular nucleus in the rat. J Anat 212: 249-256. doi:10.1111/j.1469-7580.2008.00858.x

Ceyhan M, Adapinar B, Aksaray G, Ozdemir F, Colak E. 2008. Absence and size of massa intermedia in patients with schizophrenia and bipolar disorder. Acta Neuropsychiatr 20: 193-198. doi:10.1111/j.1601-5215 .2008.00296.x

Chittajallu R, Wester JC, Craig MT, Barksdale E, Yuan XQ, Akgül G, Fang C, Collins D, Hunt S, Pelkey KA, et al. 2017. Afferent specific role of NMDA receptors for the circuit integration of hippocampal neurogliaform cells. Nat Commun 8: 152. doi:10.1038/s41467-017-00218-y

Cholvin T, Loureiro M, Cassel R, Cosquer B, Geiger K, De Sa Nogueira D, Raingard H, Robelin L, Kelche C, Pereira de Vasconcelos A, et al. 2013. The ventral midline thalamus contributes to strategy shifting in a memory task requiring both prefrontal cortical and hippocampal functions. J Neurosci 33: 8772-8783. doi:10.1523/JNEUROSCI.0771-13 .2013 
Cholvin T, Hok V, Giorgi L, Chaillan F, Poucet B. 2018. Ventral midline thalamus is necessary for hippocampal place field stability and cell firing modulation. J Neurosci 38: 158-172. doi:10.1523/JNEUROSCI.2039-17 .2017

Chudasama Y, Passetti F, Rhodes SE, Lopian D, Desai A, Robbins TW. 2003. Dissociable aspects of performance on the 5-choice serial reaction time task following lesions of the dorsal anterior cingulate, infralimbic and orbitofrontal cortex in rat: differential effects on selectivity, impulsivity and compulsivity. Behav Brain Res 146: 105-119. doi:10.1016/j.bbr .2003 .09 .020

Chudasama Y, Doobay VM, Liu Y. 2012. Hippocampal-prefrontal cortical circuit mediates inhibitory control in the rat. J Neurosci 32: 1091510924. doi:10.1523/JNEUROSCI.1463-12.2012

Ciaramelli E. 2008. The role of ventromedial prefrontal cortex in navigation: a case of impaired wayfinding and rehabilitation. Neuropsychologia 46: 2099-2105. doi:10.1016/j.neuropsychologia.2007.11.029

Clayton NS, Dickinson A. 1998. Episodic-like memory during cache recovery by scrub jays. Nature 395: $272-274$. doi:10.1038/26216

Cohen BM, Wan W, Froimowitz MP, Ennulat DJ, Cherkerzian S, Konieczna H. 1998. Activation of midline thalamic nuclei by antipsychotic drugs. Psychopharmacol (Berl) 135: 37-43. doi:10.1007/ s002130050483

Colgin LL, Moser EI, Moser MB. 2008. Understanding memory through hippocampal remapping. Trends Neurosci 31: 469-477. doi:10.1016/j .tins.2008.06.008

Cruikshank SJ, Ahmed OJ, Stevens TR, Patrick SL, Gonzales AN, Elmaleh M, Connors BW. 2012. Thalamic control of layer 1 circuits in prefrontal cortex. J Neurosci 32: 17813-17823. doi:10.1523/JNEUROSCI.3231-12 .2012

Dalley JW, Cadinal RN, Robbins TW. 2004. Prefrontal executive and cognitive functions in rodents: neural and neurochemical substrates. Neurosci Biobehav Rev 28: 771-784. doi:10.1016/j.neubiorev.2004.09 .006

DeNardo LA, Berns DS, DeLoach K, Luo L. 2015. Connectivity of mouse somatosensory and prefrontal cortex examined with trans-synaptic tracing. Nat Neurosci 18: 1687-1697. doi:10.1038/nn.4131

DeVito LM, Eichenbaum H. 2011. Memory for the order of events in specific sequences: contributions of the hippocampus and medial prefrontal cortex. J Neurosci 31: 3169-3175. doi:10.1523/JNEUROSCI.4202-10 .2011

Dolleman-van der Weel MJ, Witter MP. 1996. Projections from the nucleus reuniens thalami to the entorhinal cortex, hippocampal field CA1, and the subiculum in the rat arise from different populations of neurons. $J$ Comp Neurol 364: 637-650. doi:<637::AID-CNE3>3.0.CO;2-4

Dolleman-van der Weel MJ, Witter MP. 2000. Nucleus reuniens thalami innervates $\gamma$ aminobutyric acid positive cells in hippocampal field CA1 of the rat. Neurosci Lett 278: 145-148. doi:10.1016/S0304-3940(99) 00935-0

Dolleman-van der Weel MJ, Lopes de Silva FH, Witter MP. 1997. Nucleus reuniens thalami modulates activity in hippocampal field CA1 through excitatory and inhibitory mechanisms. J Neurosci 17: 5640-5650. doi:10 .1523/JNEUROSCI.17-14-05640.1997

Dolleman-van der Weel MJ, Morris RG, Witter MP. 2009. Neurotoxic lesions of the thalamic reuniens or mediodorsal nucleus in rats affect non-mnemonic aspects of watermaze learning. Brain Struct Funct 213: 329-342. doi:10.1007/s00429-008-0200-6

Dolleman-van der Weel MJ, Lopes de Silva FH, Witter MP. 2017. Interactions of nucleus reuniens and entorhinal cortex projections in hippocampal field CA1 of the rat. Brain Struct Funct 222: 2421-2438. doi:10.1007/ s00429-016-1350-6

Drexel M, Preidt AP, Kirchmair E, Sperk G. 2011. Parvalbumin interneurons and calretinin fibers arising from the thalamic nucleus reuniens degenerate in the subiculum after kainic acid-induced seizures. Neuroscience 189: 316-329. doi:10.1016/j.neuroscience.2011.05.021

Duan AR, Varela C, Zhang Y, Shen Y, Xiong L, Wilson MA, Lisman J. 2015. Delta frequency optogenetic stimulation of the thalamic nucleus reuniens is sufficient to produce working memory deficits: relevance to schizophrenia. Biol Psychiatry 77: 1098-1107. doi:10.1016/j.biopsych .2015 .01 .020

Dudman JT, Tsay D, Siegelbaum SA. 2007. A role for synaptic inputs at distal dendrites: instructive signals for hippocampal long-term plasticity. Neuron 56: 866-879. doi:10.1016/j.neuron.2007.10.020

Ekstrom AD, Bookheimer SY. 2007. Spatial and temporal episodic memory retrieval recruit dissociable functional networks in the human brain. Learn Mem 14: 645-654. doi:10.1101/lm.575107

Eichenbaum H. 2017. On the integration of space, time, and memory. Neuron 95: 1007-1018. doi:10.1016/j.neuron.2017.06.036

Eleore L, López-Ramos JC, Guerra-Narbona R, Delgado-García JM. 2011. Role of reuniens nucleus projections to the medial prefrontal cortex and to the hippocampal pyramidal CA1 area in associative learning. PLoS One 6: e23538. doi:10.1371/journal.pone.0023538
Euston DR, Tatsuno M, McNaughton BL. 2007. Fast-forward playback of recent memory sequences in prefrontal cortex during sleep. Science 318 : 1147-1150. doi:10.1126/science.1148979

Ferraris M, Ghestem A, Vicente AF, Nallet-Khosrofian L, Bernard C, Quilichini PP. 2018. The nucleus reuniens controls long-range hippocampo-prefrontal $\gamma$ synchronization during slow oscillations. J Neurosci 38: 3026-3038. doi:10.1523/JNEUROSCI.3058-17.2018

Fortin NJ, Agster KL, Eichenbaum HB. 2002. Critical role of the hippocampus in memory for sequences of events. Nat Neurosci 5: 458462. doi:10.1038/nn834

Frank LM, Brown EN, Wilson M. 2000. Trajectory encoding in the hippocampus and entorhinal cortex. Neuron 27: 169-178. doi:10.1016/ S0896-6273(00)00018-0

Frassoni C, Bentivoglio M, Spreafico R, Sánchez MP, Puelles L, Fairen A. 1991. Postnatal development of calbindin and parvalbumin immunoreactivity in the thalamus of the rat. Dev Brain Res 58: 243-249. doi:10.1016/0165-3806(91)90011-7

Fries P. 2015. Rhythms for cognition: communication through coherence. Neuron 88: 220-235. doi:10.1016/j.neuron.2015.09.034

Fuster JM. 1995. Memory in the cerebral cortex: an empirical approach to neural networks in the human and nonhuman primate. MIT Press, Cambridge, MA.

Gabbott P, Headlam A, Busby S. 2002. Morphological evidence that CA1 hippocampal afferents monosynaptically innervate PV-containing neurons and NADPH-diaphorase reactive cells in the medial prefrontal cortex (areas 25/32) of the rat. Brain Res 946: 314-322. doi:10.1016/ S0006-8993(02)02487-3

Graef JD, Nordskog BK, Wiggins WF, Godwin DW. 2009. An acquired channelopathy involving T-type $\mathrm{Ca}^{2+}$ channels after status epilepticus. J Neurosci 29: 4430-4441. doi:10.1523/JNEUROSCI.0198-09.2009

Granon S, Poucet B. 1995. Medial prefrontal lesions in the rat and spatial navigation: evidence for impaired planning. Behav Neurosci 109: 474484. doi:10.1037/0735-7044.109.3.474

Griffin AL. 2015. Role of the thalamic nucleus reuniens in mediating interactions between the hippocampus and medial prefrontal cortex during spatial working memory. Front Syst Neurosci 9: 25. doi:10.3389/ fnsys.2015.00029

Griffin AL, Owens CB, Peters GJ, Adelman PC, Cline KM. 2012. Spatial representations in dorsal hippocampal neurons during a tactile-visual conditional discrimination task. Hippocampus 22: 299-308. doi:10 $.1002 /$ hipo.20898

Guise KG, Shapiro ML. 2017. Medial prefrontal cortex reduces memory interference by modifying hippocampal encoding. Neuron 94: 183-192. doi:10.1016/j.neuron.2017.03.011

Hafting T, Fyhn M, Molden S, Moser MB, Moser EI. 2005. Microstructure of a spatial map in the entorhinal cortex. Nature 436: 801-806. doi:10.1038/ nature03721

Halassa MM, Acsády L. 2016. Thalamic inhibition: diverse sources, diverse scales. Trends Neurosci 39: 680-693. doi:10.1016/j.tins.2016.08.001

Hallock HL, Arreola AC, Shaw CL, Griffin AL. 2013a. Dissociable roles of the dorsal striatum and dorsal hippocampus in conditional discrimination and spatial alternation T-maze tasks. Neurobiol Learn Mem 100: 108-116. doi:10.1016/j.nlm.2012.12.009

Hallock HL, Wang A, Shaw CL, Griffin AL. 2013b. Transient inactivation of the thalamic nucleus reuniens and rhomboid nucleus produces deficits of a working-memory dependent tactile-visual conditional discrimination task. Behav Neurosci 127: 860-866. doi:10.1037/ a0034653

Hallock HL, Wang A, Griffin AL. 2016. Ventral midline thalamus is critical for hippocampal-prefrontal synchrony and spatial working memory. J Neurosci 36: 8372-8389. doi:10.1523/JNEUROSCI.0991-16.2016

Hannesson DK, Howland JG, Phillips AG. 2004. Interaction between perirhinal and medial prefrontal cortex is required for temporal order but not recognition memory for objects in rats. J Neurosci 24: 45964604. doi:10.1523/JNEUROSCI.5517-03.2004

Hardenacke K, Shubina E, Bührle CP, Zapf A, Lenartz D, Klosterkötter J, Visser-Vanderwalle V, Kuhn J. 2013. Deep brain stimulation as a tool for improving cognitive functioning in Alzheimer's dementia: a systematic review. Front Psychiatry 4: 159. doi:10.3389/fpsyt.2013.00159

Hartung H, Brockmann MD, Pöschel B, De Feo V, Hanganu-Opatz IL. 2016 Thalamic and entorhinal network activity of prefrontal-hippocampal interactions. J Neurosci 36: 3676-3690. doi:10.1523/JNEUROSCI $.3232-15.2016$

Hembrook JR, Onos KD, Mair RG. 2012. Inactivation of the ventral midline thalamus produces selective spatial delayed conditional discrimination impairment in the rat. Hippocampus 22: 853-860. doi:10.1002/hipo .20945

Herkenham M. 1978. The connections of the nucleus reuniens thalami: evidence for a direct thalamo-hippocampal pathway in the rat. J Comp Neurol 177: 589-610. doi:10.1002/cne.901770405

Hirayasu Y, Wada JA. 1992. Convulsive seizures in rats induced by N-methyl-D-aspartate injection into the massa intermedia. Brain Res 577: 36-40. doi:10.1016/0006-8993(92)90534-G 
Hoover WB, Vertes RP. 2007. Anatomical analysis of afferent projections to the medial prefrontal cortex in the rat. Brain Struct Funct 212: 149-179. doi:10.1007/s00429-007-0150-4

Hoover WB, Vertes RP. 2011. Projections of the medial orbital and ventral orbital cortex in the rat. Brain Struct Funct 212: 149-179. doi:10.1007/ s00429-007-0150-4

Hoover WB, Vertes RP. 2012. Collateral projections from nucleus reuniens of thalamus to hippocampus and medial prefrontal cortex in rat: a single and double retrograde fluorescent labeling study. Brain Struct Funct 217: 191-209. doi:10.1007/s00429-011-0345-6

Howard MW, Kahana MJ. 2002. When does semantic similarity help episodic retrieval? J Mem Lang 46: 85-98. doi:10.1006/jmla.2001.2798

Huber R, Ghilardi MF, Massimini M, Tononi G. 2004. Local sleep and learning. Nature 430: 78-81. doi:10.1038/nature02663

Hur EE, Zaborsky L. 2005. Vglut2 afferents to the medial prefrontal and primary somatosensory cortices: a combined retrograde tracing in situ hybridization study. J Comp Neurol 483: 351-373. doi:10.1002/cne .20444

Hyman JM, Zilli EA, Paley AM, Hasselmo ME. 2010. Working memory performance correlates with prefrontal-hippocampal $\theta$ interactions but not with prefrontal neuron firing rates. Front Integr Neurosci 4: 2. doi:10 $.3389 /$ neuro.07.002.2010

Ito HT, Zhang SJ, Witter MP, Moser EI, Moser MB. 2015. A prefrontal-thalamo-hippocampal circuit for goal directed spatial navigation. Nature 522: 50-55. doi:10.1038/nature14396

Ito HT, Moser EI, Moser MB. 2018. Supramammillary nucleus modulates spike-time coordination in the prefrontal-thalamo-hippocampal circuit during navigation. Neuron 99: 576-587 e575. doi:10.1016/j.neuron .2018.07.021

Izquierdo A. 2017. Functional heterogeneity within rat orbitofrontal cortex in reward learning and decision making. J Neurosci 37: 10529-10540. doi:10.1523/JNEUROSCI.1678-17.2017

Jacobs NS, Allen TA, Nguyen N, Fortin NJ. 2013. Critical role of the hippocampus in memory for elapsed time. J Neurosci 33: 13888-13893. doi:10.1523/JNEUROSCI.1733-13.2013

Jankowski MM, Islam MN, Wright NF, Vann SD, Erichsen JT, Aggleton JP, O'Mara SM. 2014. Nucleus reuniens of the thalamus contains head direction cells. Elife 3: e03075. doi:10.7554/eLife.03075

Jankowski MM, Passecker J, Islam MN, Vann S, Erichsen JT, Aggleton JP, O'Mara SM. 2015. Evidence for spatially-responsive neurons in the rostral thalamus. Front Behav Neurosci 9: 256. doi:10.3389/fnbeh.2015 .00256

Jay TM, Witter MP. 1991. Distribution of hippocampal CA1 and subicular efferents in the prefrontal cortex of the rat studied by means of anterograde transport of Phaseolus vulgaris-leucoagglutinin. J Comp Neurol 313: 574-586. doi:10.1002/cne.903130404

Jayachandran M, Linley S, Schlecht M, Mahler SV, Vertes RP, Allen TA. 2018. Prefrontal pathways provide top-down control of memory for sequences of events. bioRxiv doi:10.1101/508051

Jones EG. 1998. A new view of specific and non-specific thalamocortical connections. Adv Neurol 77: 49-71.

Jones MW, Wilson MA. 2005. $\theta$ rhythms coordinate hippocampalprefrontal interactions in a spatial memory task. PLoS Biol 3: e402. doi:10.1371/journal.pbio.0030402

Kafetzopoulos V, Kokras N, Sotiropoulos I, Oliveira JF, Leite-Almeida H, Vasalou A, Sardinha VM, Papadopoulou-Daifoti Z, Almeida OFX, Antoniou K, et al. 2018. The nucleus reuniens: a key node in the neurocircuitry of stress and depression. Mol Psychiatry 23: 579-586. doi: $10.1038 / \mathrm{mp} .2017 .55$

Kehagia AA, Murray GK, Robbins TW. 2010. Learning and cognitive flexibility: frontostriatal function and monoaminergic modulation. Curr Opin Neurobiol 20: 199-204. doi:10.1016/j.conb.2010.01.007

Kesner RP, Hunsaker MR. 2010. The temporal attributes of episodic memory. Behav Brain Res 215: 299-309. doi:10.1016/j.bbr.2009.12.029

Kesner RP, Gilbert PE, Barua LA. 2002. The role of the hippocampus in memory for the temporal order of a sequence of odors. Behav Neurosci 116: $286-290$. doi:10.1037/0735-7044.116.2.286

Klockgether T, Schwarz M, Turski L, Wolfarth S, Sontag KH. 1985. Rigidity and catalepsy after injections of muscimol into the ventromedial thalamic nucleus: an electromyographic study in the rat. Exp Brain Res 58: 559-569. doi:10.1007/BF00235872

Knierim JJ, Lee I, Hargreaves EL. 2006. Hippocampal place cells: parallel input streams, subregional processing, and implications for episodic memory. Hippocampus 16: 755-764. doi:10.1002/hipo.20203

Kragel JE, Morton NW, Polyn SM. 2015. Neural activity in the medial temporal lobe reveals the fidelity of mental time travel. J Neurosci 35: 2914-2926. doi:10.1523/JNEUROSCI.3378-14.2015

Lambe EK, Liu RJ, Aghajanian GK. 2007. Schizophrenia, hypocretin (orexin), and the thalamocortical activating system. Schizophr Bull 33: 1284-1290. doi:10.1093/schbul/sbm088

Landin-Romero R, Amann BL, Sarró S, Guerrero-Pedraza A, Vicens V, Rodriguez-Cano E, Vieta E, Salvador R, Pomarol-Clotet E, Radua J. 2016.
Midline brain abnormalities across psychotic and mood disorders Schizophr Bull 42: 229-238. doi:10.1093/schbul/sbv097

Lara-Vásquez A, Espinosa N, Durán E, Stockle M, Fuentealba P. 2016. Midline thalamic neurons are differentially engaged during hippocampal network oscillations. Sci Rep 6: 29807. doi:10.1038/ srep29807

Laroche S, Davis S, Jay TM. 2000. Plasticity at hippocampal to prefrontal cortex synapses: dual roles in working memory and consolidation. Hippocampus 10: 438-446. doi:10.1002/1098-1063(2000)10:4<438:: AID-HIPO10>3.0.CO;2-3

Lawrie SM, Buechel C, Whalley HC, Frith CD, Friston KJ, Johnstone EC. 2002. Reduced frontotemporal functional connectivity in schizophrenia associated with auditory hallucinations. Biol Psychiatry 51: 1008-1011. doi:10.1016/S0006-3223(02)01316-1

Layfield DM, Patel M, Hallock H, Griffin AL. 2015. Inactivation of the nucleus reuniens/rhomboid causes a delay-dependent impairment of spatial working memory. Neurobiol Learn Mem 125: 163-167. doi:10 $.1016 /$ j.nlm.2015.09.007

Lee I, Griffin AL, Zilli EA, Eichenbaum H, Hasselmo ME. 2006. Gradual translocation of spatial correlates of neuronal firing in the hippocampus toward prospective reward locations. Neuron 51: 639-650. doi:10.1016/j .neuron.2006.06.033

Leutgeb S, Leutgeb JK, Barnes CA, Moser EI, McNaughton BL, Moser MB. 2005. Independent codes for spatial and episodic memory in hippocampal neuronal ensembles. Science 309: 619-623. doi:10.1126/ science. 1114037

Linley SB, Gallo MM, Vertes RP. 2016. Lesions of the ventral midline thalamus produce deficits in reversal learning and attention on an odor texture set shifting task. Brain Res 1649: 110-122. doi:10.1016/j.brainres 2016.08.022

Lisman J. 2012. Excitation, inhibition, local oscillations, or large-scale loops: what causes the symptoms of schizophrenia? Curr Opin Neurobiol 22: 537-544. doi:10.1016/j.conb.2011.10.018

Lisman JE, Pi HJ, Zhang Y, Otmakhova NA. 2010. A thalamo-hippocampal-ventral tegmental area loop may produce the positive feedback that underlies the psychotic break in schizophrenia. Biol Psychiatry 68: 17-24. doi:10.1016/j.biopsych.2010.04.007

Loureiro M, Cholvin T, Lopez J, Merienne N, Latreche A, Cosquer B, Geiger K, Kelche C, Cassel JC, Pereira de Vasconcelos A. 2012. The ventral midline thalamus (reuniens and rhomboid nuclei) contributes to the persistence of spatial memory. J Neurosci 32: 9947-9959. doi:10 .1523/JNEUROSCI.0410-12.2012

Maisson DJ, Gemzik ZM, Griffin AL. 2018. Optogenetic suppression of the nucleus reuniens selectively impairs encoding during spatial working memory. Neurobiol Learn Mem 155: 78-85. doi:10.1016/j.nlm.2018.06 .010

Markus EJ, Qin YL, Leonard B, Skaggs WE, McNaughton BL, Barnes CA. 1995. Interactions between location and task affect the spatial and directional firing of hippocampal neurons. J Neurosci 15: 7079-7094. doi:10.1523/JNEUROSCI.15-11-07079.1995

McKenna JT, Vertes RP. 2004. Afferent projections to nucleus reuniens of the thalamus. J Comp Neurol 480: 115-142. doi:10.1002/cne.20342

Mei H, Logothetis NK, Eschenko O. 2018. The activity of thalamic nucleus reuniens is critical for memory retrieval, but not essential for the early phase of "off-line" consolidation. Learn Mem 25: 129-137. doi:10.1101/ $\operatorname{lm} .047134 .117$

Meyer-Lindenberg A, Poline JB, Kohn PD, Holt JL, Egan MF, Weinberger DR, Berman KF. 2001. Evidence for abnormal cortical functional connectivity during working memory in schizophrenia. Am J Psychiatry 158: $1809-1817$. doi:10.1176/appi.ajp.158.11.1809

Meyer-Lindenberg AS, Olsen RK, Kohn PD, Brown T, Egan MF, Weinberger DR, Berman KF. 2005. Regionally specific disturbance of dorsolateral prefrontal-hippocampal functional connectivity in schizophrenia. Arch Gen Psychiatry 62: 379-386. doi:10.1001/archpsyc .62.4.379

Mölle M, Born J. 2011. Slow oscillations orchestrating fast oscillations and memory consolidation. Prog Brain Res 193: 93-110. doi:10.1016/ B978-0-444-53839-0.00007-7

Montpied P, Winsky L, Dailey JW, Jobe PC, Jacobowitz DM. 1995. Alteration in levels of expression of brain calbindin D-28k and calretinin mRNA in genetically epilepsy-prone rats. Epilepsia 36: 911-921. doi:10.1111/j .1528-1157.1995.tb01635.x

Morales GJ, Ramcharan EJ, Sundararaman N, Morgera SD, Vertes RP. 2007. Analysis of the actions of nucleus reuniens and the entorhinl cortex on EEG and evoked population behavior of the hippocampus. Conf Proc IEEE Eng Med Biol Soc 2007: 2480-2484. doi:10.1109/iembs.2007 .4352831

Moretti DV, Frisoni GB, Binetti G, Zanetti O. 2011. Anatomical substrate and scalp EEG markers are correlated in subjects with cognitive impairment and Alzheimer's disease. Front Psychiatry 1: 152. doi:10.3389/fpsyt.2010 .00152 
Morris RG. 2001. Episodic-like memory in animals: psychological criteria, neural mechanisms and the value of episodic-like tasks to investigate animal models of neurodegenerative disease. Philos Trans $R$ Soc Lond B Biol Sci 356: 1453-1465. doi:10.1098/rstb.2001.0945

Moser E, Moser MB, Andersen P. 1993. Spatial learning impairment parallels the magnitude of dorsal hippocampal lesions, but is hardly present following ventral lesions. J Neurosci 13: 3916-3925. doi:10.1523/ JNEUROSCI.13-09-03916.1993

Moser EI, Kropff E, Moser MB. 2008. Place cells, grid cells, and the brain's spatial representation system. Annu Rev Neurosci 31: 69-89. doi:10.1146/ annurev.neuro.31.061307.090723

Moser EI, Roudi Y, Witter MP, Kentros C, Bonhoeffer T, Moser MB. 2014. Grid cells and cortical representation. Nat Rev Neurosci 15: 466-481. doi:10.1038/nrn3766

Nadel L. 1968. Dorsal and ventral hippocampal lesions and behavior. Physiol Behav 3: 891-900. doi:10.1016/0031-9384(68)90174-1

Nopoulos PC, Rideout D, Crespo-Facorro B, Andreasen NC. 2001. Sex differences in the absence of massa intermedia in patients with schizophrenia versus healthy controls. Schizophr Res 48: 177-185. doi:10 .1016/S0920-9964(00)00067-0

Ogundele OM, Lee CC, Francis J. 2017. Thalamic dopaminergic neurons project to the paraventricular nucleus-rostral ventrolateral medulla/C1 neural circuit. Anat Rec (Hoboken) 300: 1307-1314. doi:10.1002/ar .23528

O'Keefe J, Dostrovsky J. 1971. The hippocampus as a spatial map. Preliminary evidence from unit activity in the freely-moving rat. Brain Res 34: 171-175. doi:10.1016/0006-8993(71)90358-1

O'Keefe J, Nadel L. 1978. The hippocampus as a cognitive map. Oxford University Press, Oxford.

O'Neill PK, Gordon JA, Sigurdsson T. 2013. $\theta$ oscillations in the medial prefrontal cortex are modulated by spatial working memory and synchronize with the hippocampus through its ventral subregion. / Neurosci 33: 14211-14224. doi:10.1523/JNEUROSCI.2378-13.2013

Ottersen OP, Storm-Mathisen J. 1984. GABA-containing neurons in the thalamus and pretectum of the rodent. An immunocytochemical study. Anat Embryol (Berl) 170: 197-207. doi:10.1007/BF00319005

Overstreet-Wadiche L, McBain CJ. 2015. Neurogliaform cells in cortical circuits. Nat Rev Neurosci 16: 458-468. doi:10.1038/nrn3969

Pan WX, McNaughton N. 2004. The supramammillary area: its organization, functions and relationship to the hippocampus. Prog Neurobiol 74: 127-166. doi:10.1016/j.pneurobio.2004.09.003

Pirot S, Jay TM, Glowinski J, Thierry AM. 1994. Anatomical and electrophysiological evidence for an excitatory amino acid pathway from the thalamic mediodorsal nucleus to the prefrontal cortex in the rat. Eur J Neurosci 6: 1225-1234. doi:10.1111/j.1460-9568.1994 .tb00621.x

Postle BR. 2006. Working memory as an emergent property of the mind and brain. Neuroscience 139: 23-38. doi:10.1016/j.neuroscience.2005.06 .005

Prasad JA, Macgregor EM, Chudasama Y. 2013. Lesions of the thalamic reuniens cause impulsive but not compulsive responses. Brain Struct Funct 218: 85-96. doi:10.1007/s00429-012-0378-5

Ramanathan KR, Ressler RL, Jin J, Maren S. 2018. Nucleus reuniens is required for encoding and retrieving precise, hippocampal-dependent contextual fear memories in rats. J Neurosci 38: 9925-9933. doi:10.1523/ JNEUROSCI.1429-18.2018

Ray MA, Graham AJ, Lee M, Perry RH, Court JA, Perry EK. 2005. Neuronal nicotinic acetylcholine receptor subunits in autism: an immonohistochemical investigation in the thalamus. Neurobiol Dis 19: 366-377. doi:10.1016/j.nbd.2005.01.017

Reagh ZM, Murray EA, Yassa MA. 2017. Repetition reveals ups and downs of hippocampal, thalamic, and neocortical engagement during mnemonic decisions. Hippocampus 27: 169-183. doi:10.1002/hipo.22681

Reep RL, Corwin JV, King V. 1996. Neuronal connections of orbital cortex in rats: topography of cortical and thalamic afferents. Exp Brain Res 111: 215-232. doi:10.1007/BF00227299

Rempel-Clower NL, Zola SM, Squire LR, Amaral DG. 1996. Three cases of enduring memory impairment after bilateral damage limited to the hippocampal formation. J Neurosci 16: 5233-5255. doi:10.1523/ JNEUROSCI.16-16-05233.1996

Roy A, Svensson FP, Mazeh A, Kocsis B. 2017. Prefrontal-hippocampal coupling by $\theta$ rhythm and by $2-5 \mathrm{~Hz}$ oscillation in the delta band: the role of the nucleus reuniens of the thalamus. Brain Struct Funct 222: 2819-2830. doi:10.1007/s00429-017-1374-6

Saalman YB. 2014. Intralaminar and medial thalamic influence on cortical synchrony, information transmission and cognition. Front Syst Neurosci 8: 83 . doi: $10.3389 /$ fnsys.2014.00083

Sargolini F, Fyhn M, Hafting T, McNaughton BL, Witter MP, Moser MB, Moser EI. 2006. Conjunctive representation of position, direction, and velocity in entorhinal cortex. Science 312: 758-762. doi:10.1126/science .1125572
Shaw CL, Watson GD, Hallock HL, Cline KM, Griffin AL. 2013. The role of the medial prefrontal cortex in the acquisition, retention, and reversal of a tactile visuospatial conditional discrimination task. Behav Brain Res 236: $94-101$. doi:10.1016/j.bbr.2012.08.024

Sherman SM. 2017. Functioning of circuits connecting thalamus and cortex. Compr Physiol 7: 713-739. doi:10.1002/cphy.c160032

Siapas AG, Lubenov EV, Wilson MA. 2005. Prefrontal phase locking to hippocampal $\theta$ oscillations. Neuron 46: 141-151. doi:10.1016/j.neuron .2005 .02 .028

Sigurdsson T, Stark KL, Karayiorgou M, Gogos JA, Gordon JA. 2010. Impaired hippocampal-prefrontal synchrony in a genetic mouse model of schizophrenia. Nature 464: 763-767. doi:10.1038/nature08855

Sloan DM, Bertram EH III. 2009. Changes in midline thalamic recruiting responses in the prefrontal cortex of the rat during the development of chronic limbic seizures. Epilepsia 50: 556-565. doi:10.1111/j.1528-1167 .2008.01790.x

Spellman T, Rigotti M, Ahmari SE, Fusi S, Gogos JA, Gordon JA. 2015. Hippocampal-prefrontal input supports spatial encoding in working memory. Nature 522: 309-314. doi:10.1038/nature14445

Spiers HJ. 2008. Keeping the goal in mind: prefrontal contributions to spatial navigation. Neuropsychologia 46: 2106-2108. doi:10.1016/j .neuropsychologia.2008.01.028

Stachniak TJ, Ghosh A, Sternson SM. 2014. Chemogenetic synaptic silencing of neural circuits localizes a hypothalamus $\rightarrow$ midbrain pathway for feeding behavior. Neuron 82: 797-808. doi:10.1016/j neuron.2014.04.008

Starr MS, Summerhayes M. 1983. Role of the ventromedial nucleus of the thalamus in motor behaviour-1. Effects of focal injections of drugs. Neuroscience 10: 1157-1169. doi:10.1016/0306-4522(83)90106-9

Stefan H, Lopes da Silva FH. 2013. Epileptic neuronal networks: methods of identification and clinical relevance. Front Neurol 4: 8. doi:10.3389/ fneur.2013.00008

Takahashi T, Suzuki M, Nakamura K, Tanino R, Zhou SY, Hagino H, Kawasaki Y, Kurachi M. 2008. Association between absence of the adhesio interthalamica and amygdala volume in schizophrenia. Psychiatry Res 162: 101-111. doi:10.1016/j.pscychresns.2007.04.005

Theyel BB, Llano DA, Sherman SM. 2010. The corticothalamocortical circuit drives higher-order cortex in the mouse. Nat Neurosci 13: 84-88. doi:10 $.1038 / \mathrm{nn} .2449$

Tolman EC. 1948. Cognitive maps in rats and men. Psychol Rev 55: 189-208. doi:10.1037/h0061626

Torres-Berrío A, Vargas-López A, López-Canul M. 2019. The ventral hippocampus is required for behavioral flexibility but not for allocentric/egocentric learning. Brain Res Bull 146: 40-50. doi:10.1016/ .brainresbull.2018.12.011

Trzesniak C, Kempton MJ, Busatto GF, de Oliveira IR, Galvão-de Almeida A Kambeitz J, Ferrari MC, Filho AS, Chagas MH, Zuardi AW, et al. 2011. Adhesio interthalamica alterations in schizophrenia spectrum disorders: a systematic review and meta-analysis. Prog Neuropsychopharmacol Biol Psychiatry 35: 877-886. doi:10.1016/j.pnpbp.2010.12.024

Trzesniak C, Schauffelberger MS, Duran FL, Santos LC, Rosa PG, McGuire PK, Murray RM, Scazufca M, Menezes PR, Hallak JE, et al. 2012. Longitudinal follow-up of cavum septum pellucidum and adhesion interthalamica alterations in first episode psychosis: a population-based MRI study. Psychol Med 42: 2523-2534. doi:10.1017/ S0033291712000839

Tulving E. 2002. Episodic memory: from mind to brain. Annu Rev Psychol 53: 1-25. doi:10.1146/annurev.psych.53.100901.135114

Vanderwolf CH, Leung LW, Cooley RK. 1985. Pathways through cingulate, neo- and entorhinal cortices mediate atropine-resistant hippocampal rhythmical slow activity. Brain Res 347: 58-73.

Varela C, Kumar S, Yang JY, Wilson MA. 2014. Anatomical substrates for direct interactions between hippocampus, medial prefrontal cortex, and thalamic nucleus reuniens. Brain Struct Funct 219: 911-929. doi:10 $.1007 / \mathrm{s} 00429-013-0543-5$

Venkataraman A, Whitford TJ, Westin CF, Golland P, Kubicki M. 2012. Whole brain resting state functional connectivity abnormalities in schizophrenia. Schizophr Res 139: 7-12. doi:10.1016/j.schres.2012.04 .021

Vertes RP. 1992. PHA-L analysis of projection from the supramammillary nucleus in the rat. J Comp Neurol 326: 595-622. doi:10.1002/cne .903260408

Vertes RP. 2002. Analysis of projections from the medial prefrontal cortex to the thalamus in the rat, with emphasis on nucleus reuniens. J CompNeurol 442: 163-187. doi:10.1002/cne.10083

Vertes RP. 2004. Differential projections of the infralimbic and prelimbic cortex in the rat. Synapse 51: 32-58. doi:10.1002/syn.10279

Vertes RP. 2006. Interactions among the medial prefrontal cortex, hippocampus and midline thalamus in emotional and cognitive processing in the rat. Neuroscience 142: 1-20. doi:10.1016/j .neuroscience.2006.06.027 
Vertes RP, Hoover WB, Do Valle AC, Sherman A, Rodriguez JJ. 2006. Efferent projections of reuniens and rhomboid nuclei of the thalamus in the rat. $J$ Comp Neurol 499: 768-796. doi:10.1002/cne.21135

Vertes RP, Hoover WB, Szigeti-Buck K, Leranth C. 2007. Nucleus reuniens of the midline thalamus: link between the medial prefrontal cortex and the hippocampus. Brain Res Bull 71: 601-609. doi:10.1016/j.brainresbull 2006.12.002

Vertes RP, Linley SB, Hoover WB. 2015. Limbic circuitry of the midline thalamus. Neurosci Biobehav Rev 54: 89-107. doi:10.1016/j.neubiorev 2015.01.014

Viana Di Prisco G, Vertes RP. 2006. Excitatory actions of the ventral midline thalamus (rhomboid/reuniens) on the medial prefrontal cortex in the rat. Synapse 60: $45-55$. doi:10.1002/syn.20271

Viena TD, Linley SB, Vertes RP. 2018. Inactivation of nucleus reuniens impairs spatial working memory and behavioral flexibility in the rat Hippocampus 28: 297-311. doi:10.1002/hipo.22831

Visser PJ, Krabbendam L, Verhey FR, Hofman PA, Verhoeven WM, Tuinier S, Wester A, Den Berg YW, Goessens LF, Werf YD, et al. 1999. Brain correlates of memory dysfunction in alcoholic Korsakoff's syndrome. $J$ Neurol Neurosurg Psychiatry 67: 774-778. doi:10.1136/jnnp.67.6.774

Walsh DA, Brown JT, Randall AD. 2017. In vitro characterization of cell-level neurophysiological diversity in the rostral nucleus reuniens of adult mice. J Physiol 595: 3549-3572. doi:10.1113/JP273915

Wang X, Stewart L, Cortez MA, Wu Y, Velazquez JC, Liu CC, Shen L, Snead OC III. 2009. The circuitry of atypical absence seizures in GABA(B) R1a transgenic mice. Pharmacol Biochem Behav 94: 124-130. doi:10 $.1016 /$ j.pbb.2009.07.017

Wood ER, Dudchenko PA, Robitsek RJ, Eichenbaum H. 2000. Hippocampal neurons encode information about different types of memory episodes occurring in the same location. Neuron 27: 623-633. doi:10.1016/ S0896-6273(00)00071-4
Wouterlood FG. 1991. Innervation of entorhinal principal cells by neurons of the nucleus reuniens thalami. Anterograde PHA-L tracing combined with retrograde fluorescent tracing and intracellular injection with Lucifer Yellow in the rat. Eur J Neurosci 3: 641-647. doi:10.1111/j .1460-9568.1991.tb00850.x

Wouterlood FG, Saldana E, Witter MP. 1990. Projection from the nucleus reuniens thalami to the hippocampal region: light and electron microscopic tracing study in the rat with the anterograde tracer Phaseolus vulgaris leucoagglutinin. J Comp Neurol 296: 179-203. doi:10 $.1002 /$ cne.902960202

$\mathrm{Xu}$ W, Südhof TC. 2013. A neural circuit for memory specificity and generalization. Science 339: 1290-1295. doi:10.1126/science.1229534

Ye X, Kapeller-Libermann D, Travaglia A, Inda MC, Alberini CM. 2017. Direct dorsal hippocampal-prelimbic cortex connections strengthen fear memories. Nat Neurosci 20: 52-61. doi:10.1038/nn.4443

Zhang DX, Bertram EH. 2002. Midline thalamic region: widespread excitatory input to the entorhinal cortex and amygdala. J Neurosci 22: 3277-3284. doi:10.1523/JNEUROSCI.22-08-03277.2002

Zhang Y, Yoshida T, Katz DB, Lisman JE. 2012. NMDA antagonist action in thalamus imposes delta oscillations on the hippocampus. J Neurophysiol 107: 3181-3189. doi:10.1152/jn.00072.2012

Zimmerman EC, Grace AA. 2018. Prefrontal cortex modulates firing pattern in the nucleus reuniens of the midline thalamus via distinct corticothalamic pathways. Eur J Neurosci 48: 3255-3277. doi:10.1111/ ejn.14111

Received February 15, 2019; accepted in revised form April 16, 2019. 


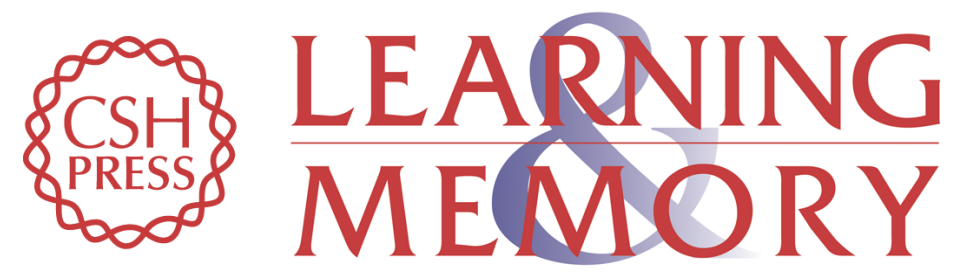

\section{The nucleus reuniens of the thalamus sits at the nexus of a hippocampus and medial prefrontal cortex circuit enabling memory and behavior}

Margriet J. Dolleman-van der Weel, Amy L. Griffin, Hiroshi T. Ito, et al.

Learn. Mem. 2019, 26:

Access the most recent version at doi:10.1101/lm.048389.118

References This article cites 181 articles, 36 of which can be accessed free at: http://learnmem.cshlp.org/content/26/7/191.full.html\#ref-list-1

Creative This article, published in Learning \& Memory, is available under a Creative Commons Commons License (Attribution-NonCommercial 4.0 International), as described at License http://creativecommons.org/licenses/by-nc/4.0/.

Email Alerting Receive free email alerts when new articles cite this article - sign up in the box at the Service top right corner of the article or click here. 